\title{
Optical clearing methods: An overview of the techniques used for the imaging of 3D spheroids
}

\author{
${\text { Elisabete C. } \text { Costa }^{1 *} \mid \text { Daniel N. Silva }}^{1 *} \mid$ André F. Moreira $^{1} \mid$ Ilídio J. Correia $^{1,2}$ ()
}

${ }^{1}$ CICS-UBI, Centro de Investigação em Ciências da Saúde, Universidade da Beira Interior, Covilha, Portugal

${ }^{2} \mathrm{CIEPQF}$, Departamento de Engenharia Química, Universidade de Coimbra, Coimbra, Portugal

\section{Correspondence}

Ilídio J. Correia, CICS-UBI, Health Sciences Research Centre, Universidade da Beira Interior, Avenida Infante D. Henrique, 6200-506 Covilha, Portugal.

Email: icorreia@ubi.pt

Funding information

Fundação para a Ciência e a Tecnologia, Grant/Award Numbers: SFRH/BD/103507/ 2014, SFRH/BD/109482/2015

\begin{abstract}
Spheroids have emerged as in vitro models that reproduce in a great extent the architectural microenvironment found in human tissues. However, the imaging of $3 \mathrm{D}$ cell cultures is highly challenging due to its high thickness, which results in a lightscattering phenomenon that limits light penetration. Therefore, several optical clearing methods, widely used in the imaging of animal tissues, have been recently explored to render spheroids with enhanced transparency. These methods are aimed to homogenize the microtissue refractive index (RI) and can be grouped into four different categories, namely (a) simple immersion in an aqueous solution with high RI; (b) delipidation and dehydration followed by RI matching; (c) delipidation and hyperhydration followed by RI matching; and (d) hydrogel embedding followed by delipidation and RI matching. In this review, the main optical clearing methods, their mechanism of action, advantages, and disadvantages are described. Furthermore, the practical examples of the optical clearing methods application for the imaging of $3 \mathrm{D}$ spheroids are highlighted.
\end{abstract}

\section{KEYWORDS}

imaging, light scattering, optical clearing, optical microscopy, spheroids.

\section{1 | INTRODUCTION}

In the early years of the 20th century, cell culture techniques (i.e., cell proliferation in environmentally controlled conditions) emerged as a powerful methodology to study and understand the behavior of the cells within the human body (Souza, Ferreira, Marangoni, Bastos, \& Goulart, 2016). Such approach allowed the characterization of the cellular differentiation, migration, proliferation, and mechanics, as well as their response to external stimuli (e.g., drugs, environment changes, and mechanical stress; Souza et al., 2016). In this way, researchers could decipher the background of several in vivo processes, such as the tissue development and the pathophysiology of the diseases (Hudu, Alshrari, Syahida, \& Sekawi, 2016; Souza et al., 2016). Therefore, in vitro culture of cells is now broadly used in several fields, such as cancer research, tissue regeneration, gene

*Elisabete C. Costa and Daniel N. Silva contributed equally to this work. therapy, and drug screening, among others (Duval et al., 2017; Kapałczyńska et al., 2018).

In literature, 2D cell cultures (i.e., the culture of cells as monolayers attached to a plastic or glass surface) are the most attractive for research purposes, due to its simplicity, reproducibility, and low cost (Kapałczyńska et al., 2018). Nevertheless, different studies have been demonstrating that $2 \mathrm{D}$ cellular systems display biochemical profiles and bioactivities divergent from those observed in vivo, which is correlated with the lack of capacity of these cell culture models to reproduce the 3D cellular organization (Edmondson, Broglie, Adcock, \& Yang, 2014; Kapałczyńska et al., 2018). For instance, Sandberg \& Ernberg (2005) reported that $\approx 30 \%$ of the 7,000 genes analyzed in different cell lines showed a statistically significant differential gene expression when compared to their original tissues. Thus, 3D cell cultures, such as spheroids, have received great attention from the research community, as these in vitro models can represent more accurately the different properties of human tissues, such as liver (Yoon, Lee, Lee, \& Lee, 2015), thyroid 
(Cirello et al., 2017), cartilage (Jukes et al., 2008), pancreatic tissue (Lumelsky et al., 2001), cardiac muscle (Kehat et al., 2001) or of solid tumors (e.g., breast, colon, pancreas, prostate, ovary, among others (Eiraku et al., 2008; Eiraku et al., 2011; Ham et al., 2018; Ham, Joshi, Luker, \& Tavana, 2016; Hamilton, 1998; Khawar et al., 2018; Lazzari et al., 2018; Suga et al., 2011)). Spheroids are microtissues with a diameter within hundreds of micrometers to few millimeters that present a spatial architecture, cellular organization, cell-cell, and cell-extracellular matrix interactions quite similar to those found in the human tissues (as reviewed in detail elsewhere (Costa et al., 2016; Duval et al., 2017)).

On the other hand, the microscopy techniques (e.g., optical and fluorescence microscopy) arise as one of the easiest, low cost, and safe methodologies for the analysis of in vitro samples (Genina, Bashkatov, \& Tuchin, 2010). Particularly, the fluorescence microscopy assumes great importance since it allows the observation of fluorescent markers that stain a specific area or molecule of interest within the cells (Graf \& Boppart, 2010). Furthermore, the fluorescence microscopy also supports the acquisition of images with high resolution of the subcellular structures when the cells are cultured as monolayers. However, the imaging of large 3D spheroids by fluorescence microscopy is challenging due to their thickness and to the light-scattering phenomenon. The light scatter results from the mismatches between the cellular constituents refractive index (RI) that prompt the dispersion of the excitation light through the sample and thus limiting its penetration, or by decreasing the amount of emitted light that reaches the detector (Richardson \& Lichtman, 2015). For this reason, it is difficult to obtain high-resolution images of intact spheroids, especially from its interior (Achilli, Meyer, \& Morgan, 2012). Therefore, researchers often use thin slices of spheroids $(5-7 \mu \mathrm{m})$ to obtain images at a submicron resolution by fluorescence microscopy (Costa et al., 2016; Graf \& Boppart, 2010). Notwithstanding, the spheroids sectioning is a laborious and timeconsuming process that can permanently alter the spheroid initial structure (e.g., distort, disrupt, fold, compress or stretch; Langenbach et al., 2011; Richardson \& Lichtman, 2015). In addition, the postacquisition 3D reconstruction of the slices performed using computer software may introduce artifacts in the images (Richardson \& Lichtman, 2015). Another approach for the imaging of the deeper regions of intact spheroids is the utilization of optical sectioning microscopies, such as confocal laser scanning microscopy (CLSM), multiphoton microscopy (MPM; e.g., two-photon microscopy [2PM]), and light-sheet fluorescence microscopy (LSFM; e.g., single [or selective] plane illumination microscopy [SPIM]; Table 1; reviewed in detail in (Graf \& Boppart, 2010; Santi, 2011)). These microscopic techniques are capable of acquiring images of a thin single plane of the sample (so-called "stack") with minimal interference of the remaining parts of the sample. Then, the $3 D$ reconstruction of

TABLE 1 Comparison of the optical sectioning microscopy techniques that can be used for the imaging of 3D spheroids

\begin{tabular}{|c|c|c|c|}
\hline Technique & Confocal laser scanning microscopy & $\begin{array}{l}\text { Multiphoton microscopy (e.g., } \\
\text { two-photon microscopy) }\end{array}$ & $\begin{array}{l}\text { Light-sheet-based fluorescence } \\
\text { microscopy (e.g., single [or selective] plane } \\
\text { illumination microscopy) }\end{array}$ \\
\hline Concept & $\begin{array}{l}\text { - Optical sections are produced } \\
\text { by scanning the sample point- } \\
\text { by-point with a laser beam } \\
\text { focused on the sample; } \\
\text { - Uses a pinhole to exclude out- } \\
\text { of-focus background } \\
\text { fluorescence from detection. }\end{array}$ & $\begin{array}{l}\text { - Uses localized nonlinear excitation to } \\
\text { excite fluorescence only within a thin } \\
\text { plane; } \\
\text { - More than one photon is emitted by a } \\
\text { pulsed infrared laser source at a time } \\
\text { to excite a fluorophore. }\end{array}$ & $\begin{array}{l}\text { - A sheet plane of light illuminates a plane } \\
\text { within a sample; } \\
\text { - The illumination is done perpendicularly } \\
\text { to the direction of the imaging axis. }\end{array}$ \\
\hline $\begin{array}{l}\text { Optical } \\
\text { sectioning }\end{array}$ & Yes & Yes & Yes \\
\hline $\begin{array}{l}\text { Light scatter } \\
\text { influence }\end{array}$ & +++ & + & +++ \\
\hline $\begin{array}{l}\text { Penetration } \\
\text { depth }\end{array}$ & $\approx 100 \mu \mathrm{m}$ & up to $1 \mathrm{~mm}$ & $>1 \mathrm{~cm}$ \\
\hline Resolution & $<$ micron & $<$ micron & micron \\
\hline Photodamage & +++ & ++ & + \\
\hline Handling & + & + & +++ \\
\hline Time & +++ & ++ & ++ \\
\hline Equipment cost & ++ & +++ & + \\
\hline References & $\begin{array}{l}\text { Benninger and Piston (2013); Combs } \\
\text { and Shroff (2017); Costa et al. } \\
\text { (2016); Genina et al. (2010); } \\
\text { Marques et al. (2015) }\end{array}$ & $\begin{array}{l}\text { Benninger and Piston (2013); Combs and } \\
\text { Shroff (2017); Costa et al. (2016); Genina } \\
\text { et al. (2010); Marques et al. (2015); } \\
\text { Zipfel, Williams, and Webb (2003) }\end{array}$ & $\begin{array}{l}\text { Benninger and Piston (2013); Combs and } \\
\text { Shroff (2017); Costa et al. (2016); } \\
\text { Feuchtinger, Walch, and Dobosz (2016); } \\
\text { Genina et al. (2010); Marques et al. } \\
\text { (2015); Reynaud et al. (2008); Santi } \\
\text { (2011) }\end{array}$ \\
\hline
\end{tabular}

+: Low; ++: moderate; +++: high. 
TABLE 2 Refractive index of several cellular components

\begin{tabular}{|lll|}
$\begin{array}{l}\text { Cellular } \\
\text { component }\end{array}$ & $\begin{array}{l}\text { Refractive } \\
\text { index }\end{array}$ & Ref(s) \\
\hline Cell membrane & 1.46 & Bigio and Bown (2004) \\
\hline Cytoplasm & $1.36-1.39$ & Bassnett (2009); Choi et al. (2007); Zhang et al. (2017) \\
\hline DNA & 1.44 & Bigio and Bown (2004) \\
\hline Lipids & $1.39-1.48$ & Bigio and Bown (2004); Feuchtinger, Walch, and Dobosz (2016); Zhang et al. (2017) \\
\hline Lysosome & 1.6 & Wilson, Cottrell, and Foster (2007) \\
\hline Mitochondria & $1.36-1.42$ & Haseda et al. (2015); Zhang et al. (2017) \\
\hline Nucleus & $1.36-1.39$ & Bassnett (2009); Choi et al. (2007) \\
\hline Proteins & $1.38-1.43$ & Bigio and Bown (2004); Genina et al. (2010) \\
\hline Water & 1.33 & Bigio and Bown (2004) \\
\hline Organelles & $1.33-1.35$ & Feuchtinger et al. (2016) \\
\hline
\end{tabular}

different stacks allows the observation of a great part or even the totality of the sample (Richardson \& Lichtman, 2015). In particular, LSFM is the fluorescence-based microscopy technique with the highest penetration depth $(>1 \mathrm{~cm})$, and therefore has been broadly used for the imaging of intact spheroids (Achilli et al., 2012; Benninger \& Piston, 2013; Combs \& Shroff, 2017; Costa et al., 2016; Desmaison et al., 2018; Feuchtinger, Walch, \& Dobosz, 2016; Genina et al., 2010; Gualda, Simão, Pinto, Alves, \& Brito, 2014; Marques, Oliveira, Chang, Paula-Neto, \& Menezes, 2015; Masson et al., 2015; Paiè, Bragheri, Bassi, \& Osellame, 2016; Pampaloni, Ansari, \& Stelzer, 2013; Reynaud, Kržič, Greger, \& Stelzer, 2008; Santi, 2011; Schmitz, Fischer, Mattheyer, Pampaloni, \& Stelzer, 2017; Smyrek \& Stelzer, 2017; Weber et al., 2015; Wenzel et al., 2014).

Alternatively, to perform the imaging of intact spheroids researchers can employ optical clearing methods before samples are analyzed by microscopy. These methods aim to reduce the light-scattering phenomenon in the biological samples, rendering samples with increased transparency that promotes deeper imaging, as well as the cells structural and functional analysis (discussed hereafter).

\section{LIGHT SCATTERING AND TACTICS OF OPTICAL CLEARING}

Fluorescence imaging of biological samples is quite challenging due to the limited light penetration, which is influenced by the optical properties of the acellular and cellular sample's constituents. In this way, the light absorption by molecules, such as hemoglobin, myoglobin, and melanin, present in some tissues will reduce the light intensity that reaches both the deeper regions of the tissue (excitation light) and the detector (emitted light; Richardson \& Lichtman, 2015). Therefore, the sample bleaching allows to minimize or even prevent the light absorption by the endogenous pigments. In fact, different methodologies can be explored to reduce the light absorption by heme (major light absorber and the most abundant chromophore in the body): (a) sample can be treated with hydrogen peroxide that oxidizes the pigment (Azaripour et al., 2016); (b) samples washing with highly acidic or basic solutions that lead to the heme dissociation from hemoglobin (Susaki \& Ueda, 2016); and (c) sample incubation with aminoalcohols (e.g., N,N,N,N-tetrakis(2-hydroxypropyl) ethylenediamine) that elute the heme chromophore from hemoglobin (Susaki \& Ueda, 2016).

On the other hand, the limited light penetration in tissues and spheroids can also be attributed to the nonhomogeneous RI (i.e., how light propagates through a given substance compared to vacuum conditions) through the sample and consequent light refraction ( Table 2; Richardson \& Lichtman, 2015). For instance, the cells' lipids and proteins present high RI values ( $\approx 1.44$ and $\approx 1.43$, respectively), while cells' cytoplasm presents the lower RI $(\approx 1.35$; Feuchtinger et al., 2016; Seo, Choe, \& Kim, 2016; Susaki \& Ueda, 2016). These RI mismatches induce changes on the speed and angle of the light (visible and near-infrared region) propagation, that is, light refraction from molecules, membranes, organelles, and cells (Figure 1; Richardson \& Lichtman, 2015). This phenomenon promotes light scattering and it is the main cause of tissues opacity. The light dispersion through the sample difficult its penetration into deeper regions and decreases its intensity (Figure 1; Keereweer et al., 2013). In this way, the light penetration is usually limited to a range of $100-150 \mu \mathrm{m}$, which is insufficient for the imaging of the spheroids whole volume (Grist, Nasseri, Poon, Roskelley, \& Cheung, 2016; Richardson \& Lichtman, 2015). On the other hand, the fluorescence light resulting from the excited fluorophore can also be scattered and therefore it may not reach the detector with high intensity or indicate inaccurately its origin, which results in images with poor resolution and contrast (Keereweer et al., 2013). Hence, several optical clearing approaches have been investigated to homogenize the RI across the sample and consequently reduce the light-scattering phenomenon. This process renders 3D large biological samples with higher transparency and therefore improves the light penetration, imaging depth, and contrast, that is, the majority of the light will attain the focus point and then the majority of the fluorescence light will be detected without suffering deviations in its path (Figure 1). 


\section{Non-optical cleared spheroid}

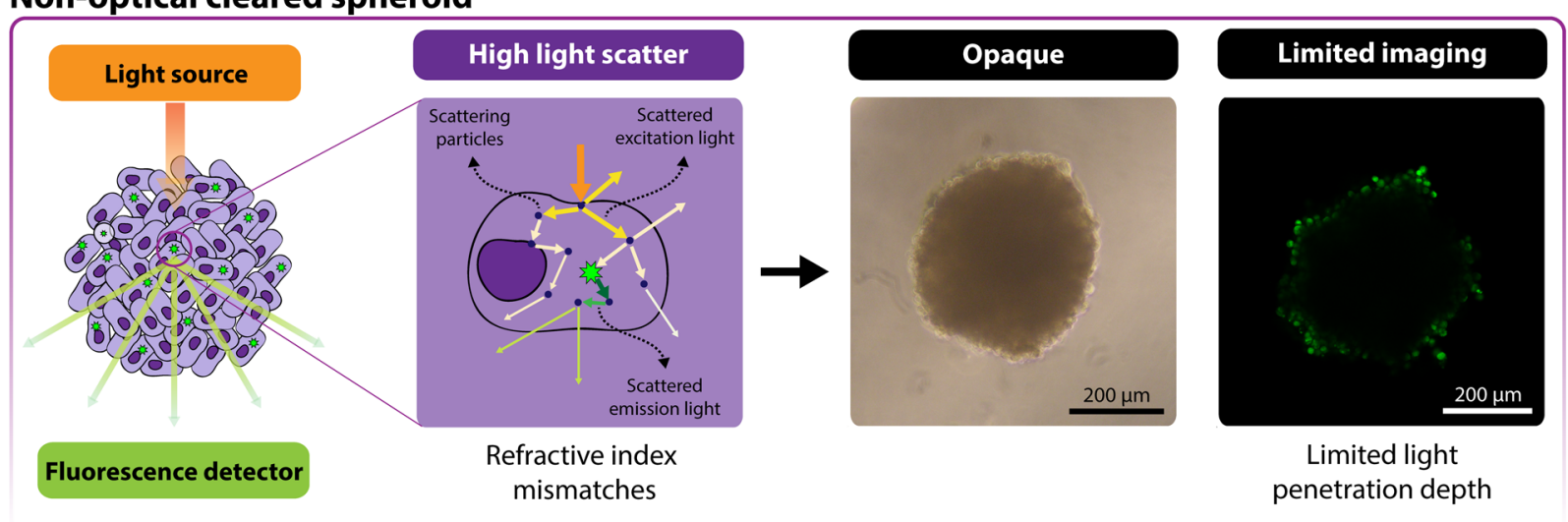

\section{Optical cleared spheroid}
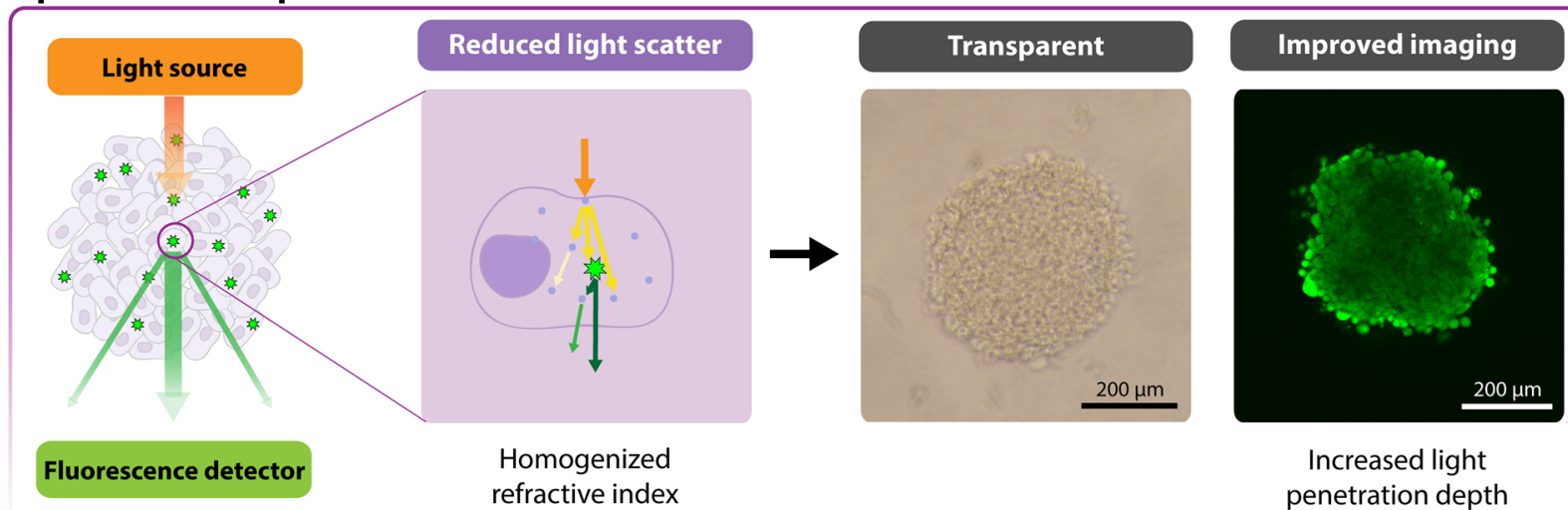

Increased light penetration depth

FIGURE 1 Representation of the light propagation in a noncleared and cleared spheroid. A noncleared spheroid has several mismatches in the refractive indexes (RI) of its constituents inducing the light scattering and consequently light dispersion through the spheroids, which results in opaque samples that do not allow deep imaging. A cleared spheroid has a transparent appearance due to the homogenization of the RI of its cellular constituents and consequently, light penetrates deeper in the spheroid making possible the imaging of the inner regions [Color figure can be viewed at wileyonlinelibrary.com]

\section{3 | CLASSIFICATION OF THE OPTICAL CLEARING METHODS}

Optical clearing methods are used to modify the optical properties of biological samples by removing, replacing, and modifying some of its components, to match the overall RI. These methods can be divided into four major groups according to their basic procedures, as previously reported (Seo et al., 2016): (a) simple immersion in an aqueous solution with high RI; (b) delipidation and dehydration followed by RI matching; (c) delipidation and hyperhydration followed by RI matching; and (d) hydrogel embedding followed by delipidation and RI matching (Figure 2 and Table 3).

The clearing methods were originally developed for processing large samples obtained from animals (e.g., bone, brain, embryo, heart, intestine, kidney, lung, muscle, pancreas, spinal cord, spleen, testis, among others), as already reviewed in detail in (Feuchtinger et al., 2016; Genina et al., 2010; Lee, Kim, \& Sun, 2016; Richardson \& Lichtman, 2015; Seo et al., 2016; Silvestri, Costantini, Sacconi, \& Pavone, 2016; Susaki \& Ueda, 2016; Tainaka, Kuno, Kubota, Murakami, \& Ueda, 2016; Tuchin, 2015; Yu, Qi, Gong, Luo, \& Zhu, 2018; Zhu, Larin, Luo, \& Tuchin, 2013). Herein, the basic concepts and mechanisms of the different clearing methods are presented, highlighting their application in the handling of spheroids samples. For sake of brevity, only the 3D imaging of solvent-cleared organs (3DISCO) and its derivatives, BABB, CLARITY and its derivatives, Clear $^{T}$, Clear ${ }^{T 2}$, CUBIC, FocusClear ${ }^{T M}$, Scale, See Deep Brain (SeeDB), Spalteholz's technique, and TDE (2,2'-thiodiethanol) will be described.

\subsection{Simple immersion in an aqueous solution with high RI}

This group includes the SeeDB, TDE, Clear ${ }^{T}, \mathrm{Clear}^{T 2}$, and FocusClear ${ }^{\mathrm{TM}}$ clearing methods. In these methods, biological samples are gradually cleared by immersing them in aqueous solutions that have a high RI (1.4-1.5; Figure 2; Ariel, 2017; Seo et al., 2016). Due to the osmotic pressure, the water content in the sample (that has low $\mathrm{RI} \approx 1.33$ ) will be passively replaced by the clearing solution. Therefore, the average $\mathrm{RI}$ of the sample will be homogenized to 1.4-1.5 since the clearing solution $\mathrm{RI}$ value match that exhibited by proteins $(\mathrm{RI} \approx 1.43)$ and lipids (RI 1.44; Feuchtinger et al., 2016).

These immersion techniques are simple, easy to perform, and low cost (Genina et al., 2010). Additionally, the absence of detergents 
Simple immersion in an aqueous solution with high RI

\section{SeeDB $(R I \approx 1.48)$}

TDE $(R I \approx 1.42)$

$\operatorname{Clear}^{T}(\mathrm{RI} \approx 1.44)$

$\operatorname{Clear}^{T_{2}}(\mathrm{RI} \approx 1.44)$

FocusClear $^{\mathrm{TM}}(\mathrm{RI} \approx 1.47)$

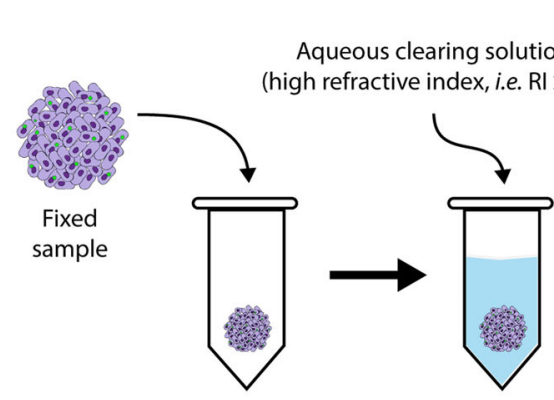

西 1.4)
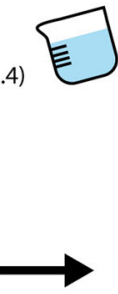
(the water is pulled out of the cells by osmotic pressure and then the clearing solution enters)
$\mathrm{Rl}$ of the clearing solution match to that of proteins and lipids

\section{Delipidation and dehydration followed by RI matching}

\section{Spatleholz $(\mathrm{RI} \approx 1.55)$}

\section{$\mathrm{BABB}(\mathrm{RI} \approx 1.55)$}

3DISCO (RI $\approx 1.56)$

IDISCO (RI $\approx 1.56)$

UDISCO $(\mathrm{RI} \approx 1.56)$

FDISCO $(R I \approx 1.56)$
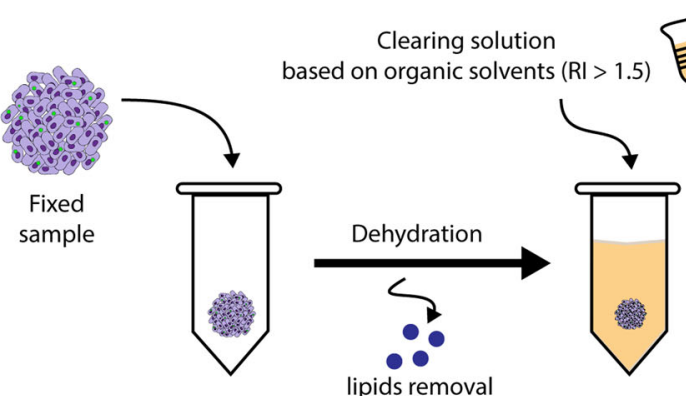

Rl of the solvent will match to that of dehydrated proteins

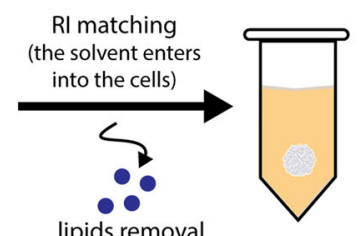

\section{Delipidation and hyperhydration followed by RI matching}

\section{Scale $(R \mid \approx 1.38)$}

\section{CUBIC (RI $\approx 1.38-1.48)$}

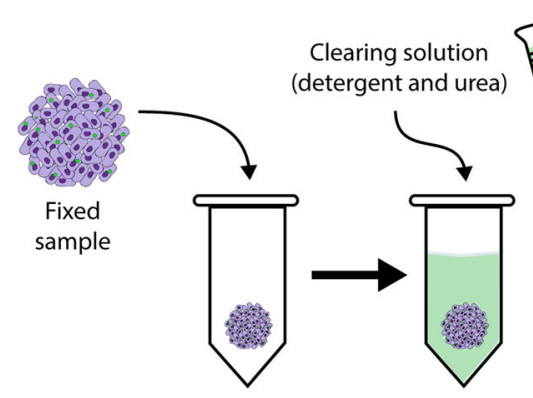

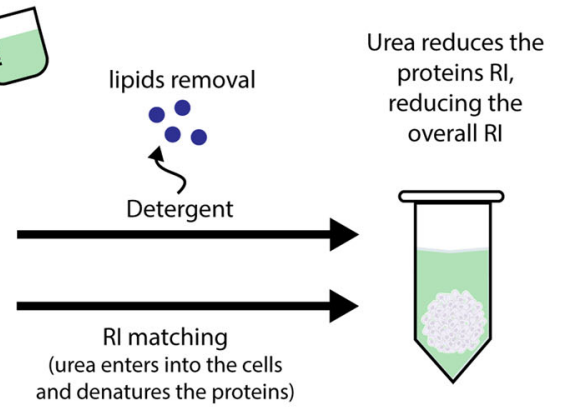

Hydrogel embedding followed by delipidation and RI matching

CLARITY $(R I \approx 1.45)$

PACT (RI 1.38-1.48)

PARS $(R I \approx 1.38-1.48)$
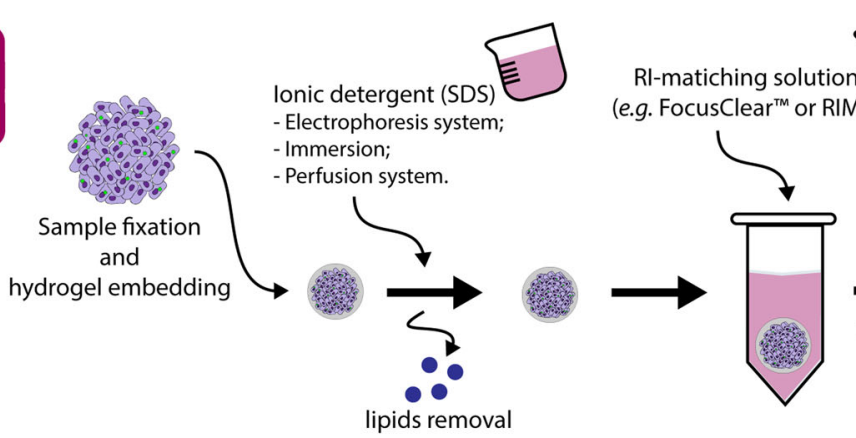

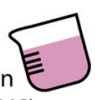
S)

RI-matching solution renders transparency

FIGURE 2 Overview of the three major groups of optical clearing methods: simple immersion in an aqueous solution with high refractive index (RI); delipidation and dehydration followed by RI matching; delipidation and hyperhydration followed by RI matching; and hydrogel embedding followed by delipidation and RI matching. The final sample RI generally obtained with each of the clearing methods is also displayed [Color figure can be viewed at wileyonlinelibrary.com] 


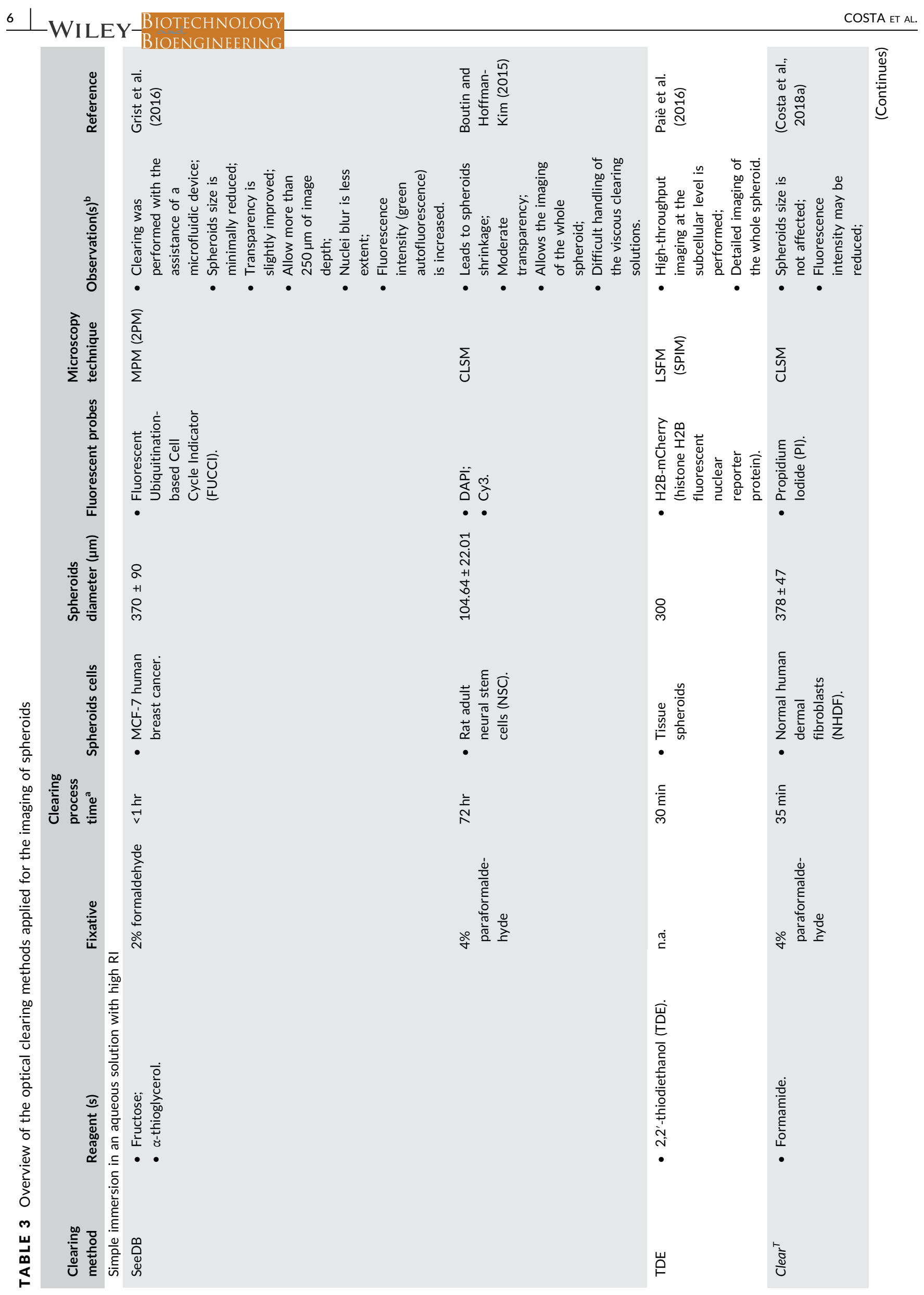




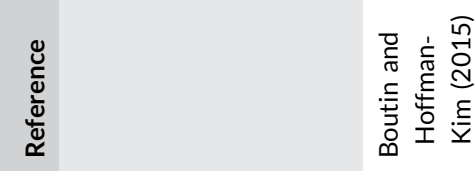

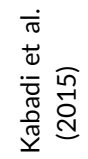

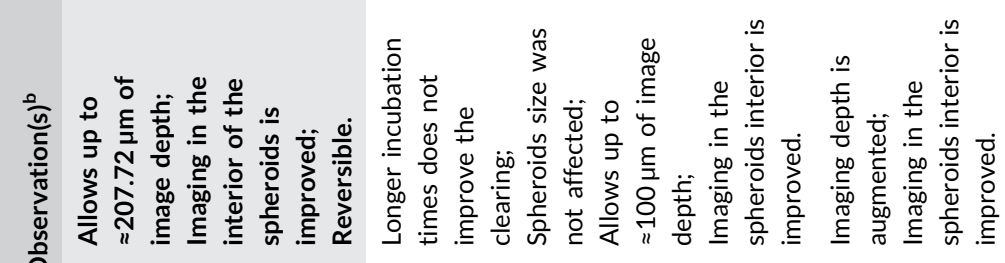

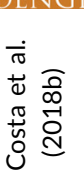

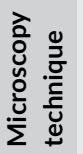

$\sum_{u}^{u}$

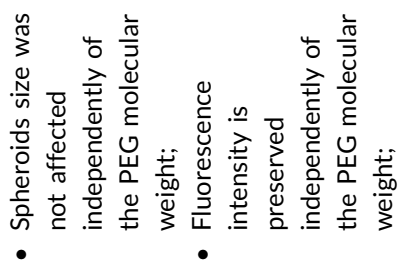

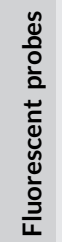

$\sum_{U}^{\cup}$

$\sum_{\text {uี }} \quad \sum_{\text {Uี }}$

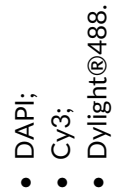

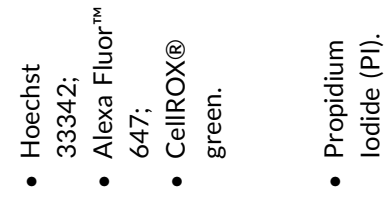

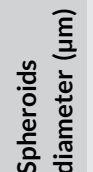

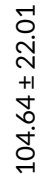

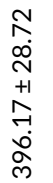

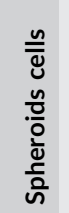

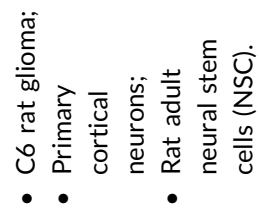

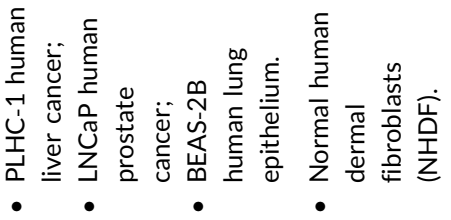

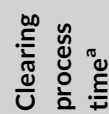

$\stackrel{\substack{\varepsilon\\}}{h}$

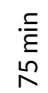

$\frac{\sqrt{E}}{n}$

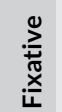

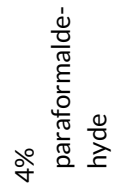

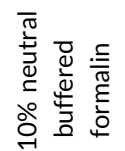

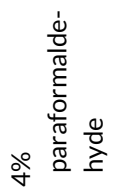

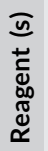

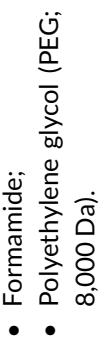

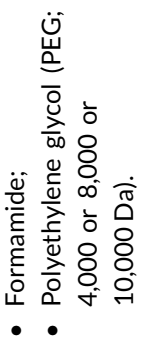

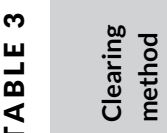

$\frac{\bar{d}}{\frac{d}{d}}$ 


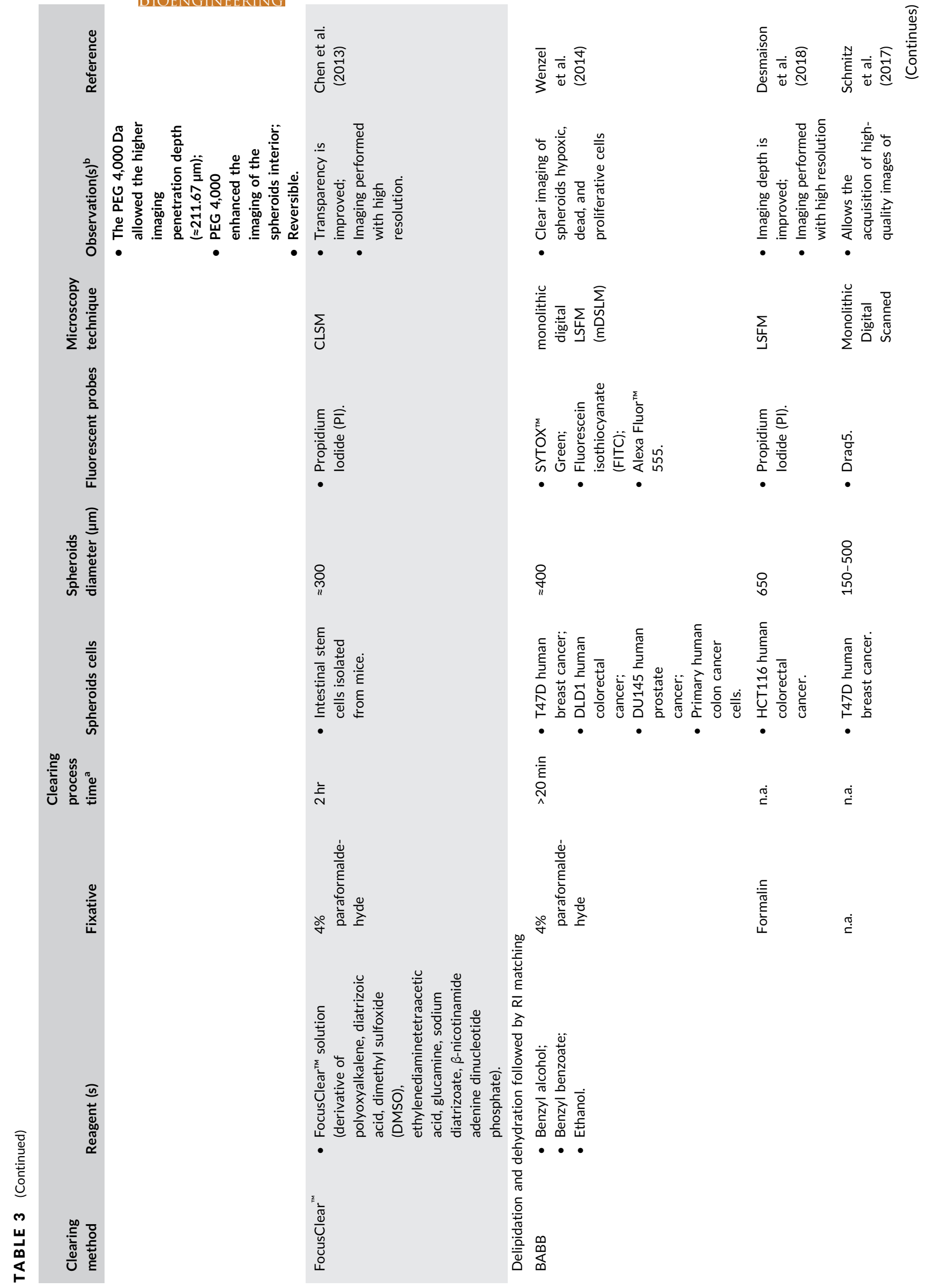




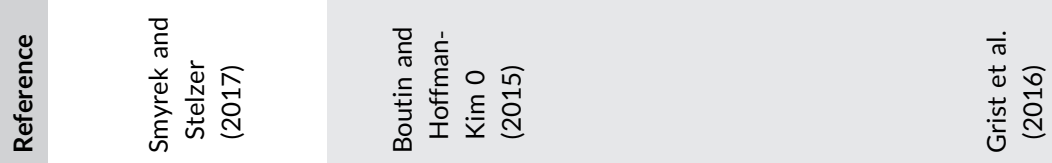

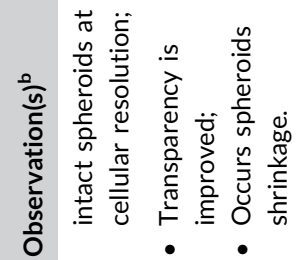

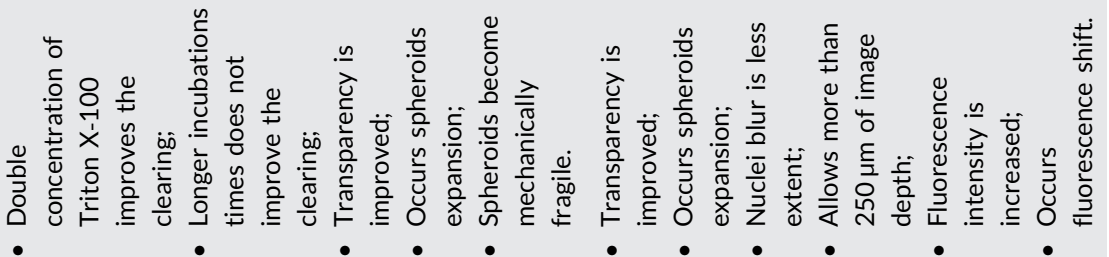

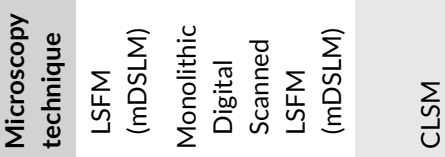

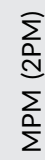

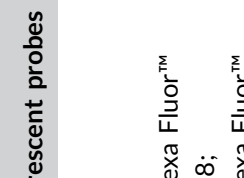

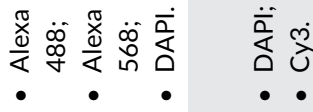

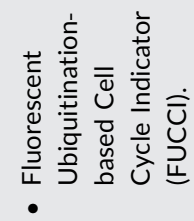

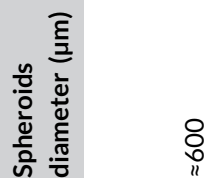

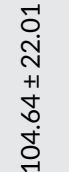

2
8
8
0
0
0

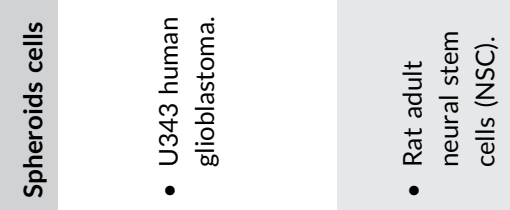

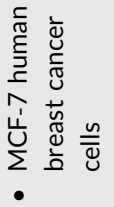

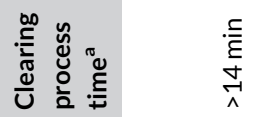

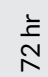

$\stackrel{\grave{c}}{\vec{v}}$

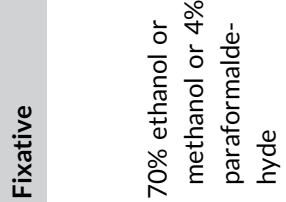

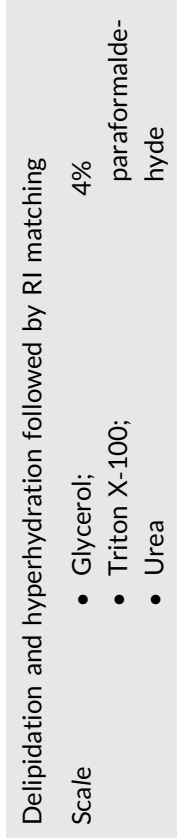

ลे

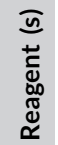

$m$
$山$
$\stackrel{m}{m}$

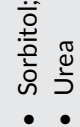




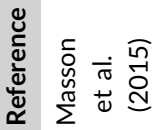

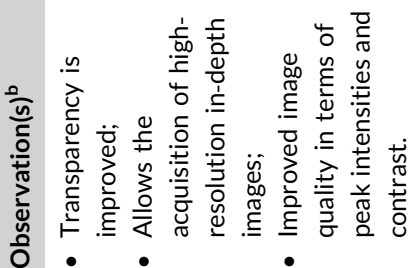

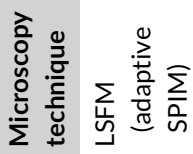

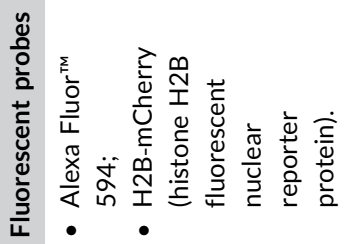

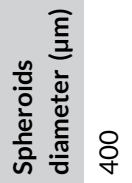

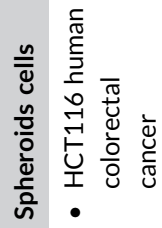

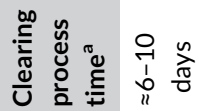
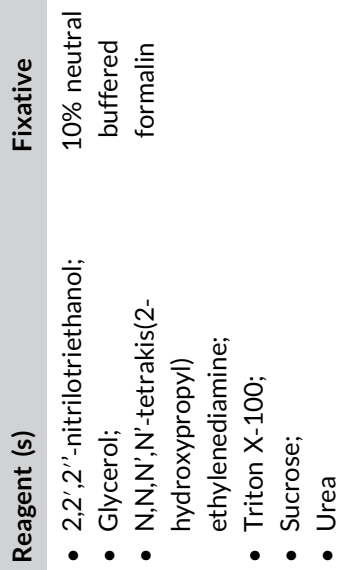

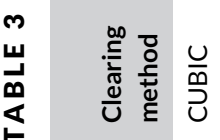

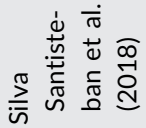

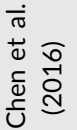

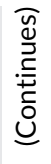

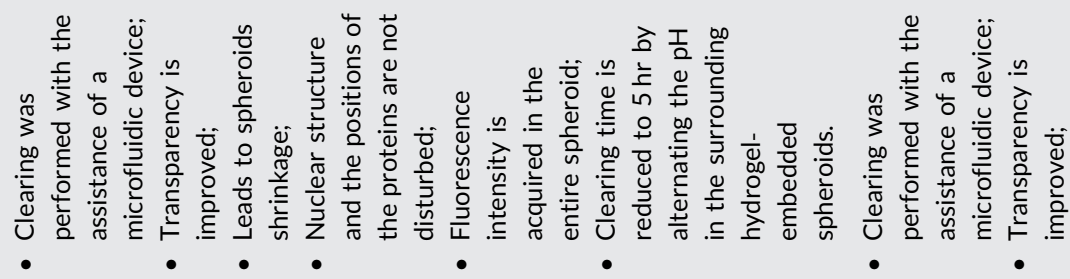

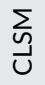
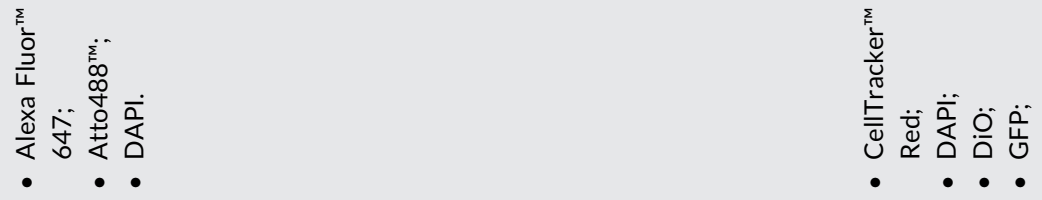

0
in
+1
$\stackrel{2}{1}$

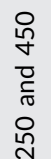
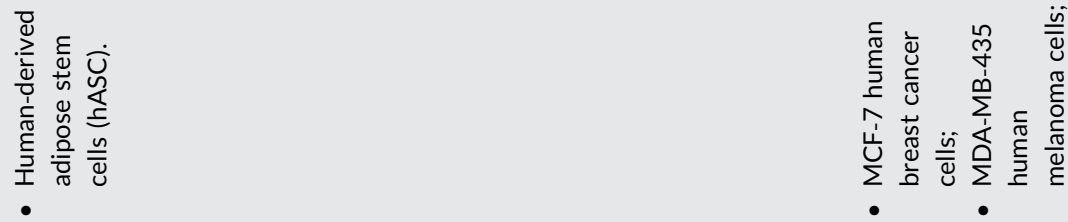

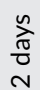

亨

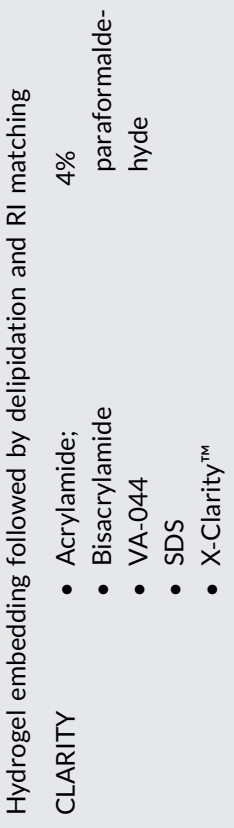

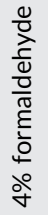

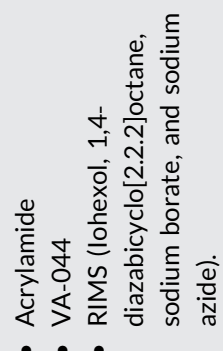


$\frac{\mathscr{\Xi}}{\frac{0}{d}}$

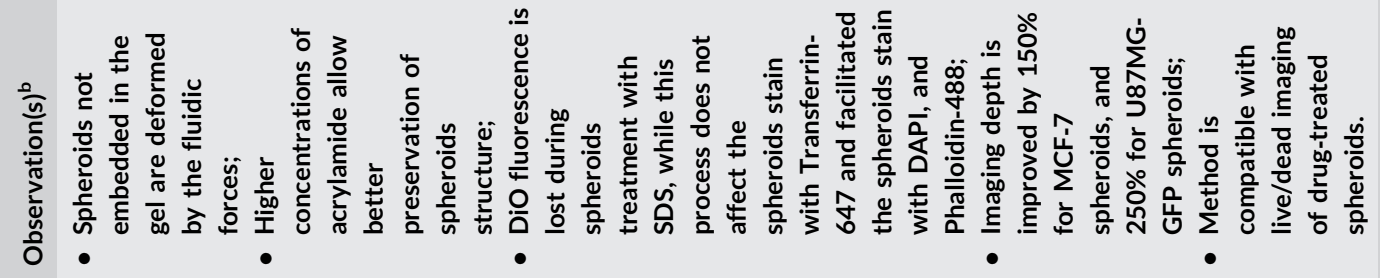

亳

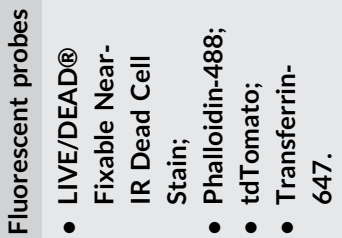

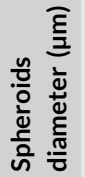

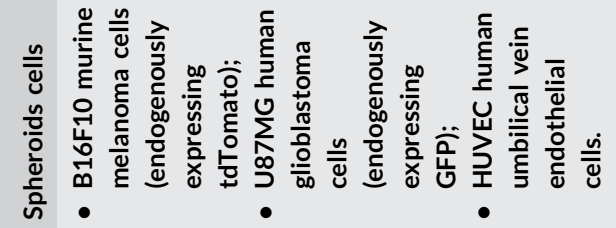

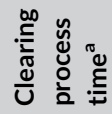

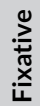

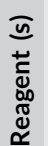

$m$
$\omega$
$m$ 
preserves the lipidic content of each sample, thus allowing the imaging of these structures using lipophilic tracer dyes (e.g., Dil and FM 1-43FX; Yu et al., 2018). Nevertheless, the preservation of the lipid content (which are one of the main factors responsible for light scattering in biological tissues) restricts the sample transparency (Tuchin, 2015). Furthermore, the incorporation of the aqueous clearing solution in the sample may induce an increase in the sample volume and consequently change its initial structure (Richardson \& Lichtman, 2015). Such also impacts on the imaging of the whole spheroid due to the increased image acquisition time and postprocessing issues (Lee et al., 2016). Lastly, since these methods rely on the passive diffusion of the solutions into the sample, the clearing process may need extensive incubation times depending on the sample size (Lee et al., 2016; Seo et al., 2016).

\subsection{1 | See Deep Brain}

The RI of the biological samples' constituents can be homogenized by immersing them in sugar-based aqueous solutions that have a high RI. In this way, Ke, Fujimoto, and Imai (2013) used fructose to develop the See Deep Brain (SeeDB) method that was applied for the clearing of large mouse samples, like whole embryos and neonatal brains. In SeeDB method, samples are successively immersed in 20,40 , and $60 \%(\mathrm{w} / \mathrm{v})$ fructose aqueous solutions during 4-8 hr, followed by their incubation in $80 \%$ fructose during $12 \mathrm{hr}$ and lastly in the SeeDB solution (RI $\approx 1.49$ at $25^{\circ} \mathrm{C} ; 115 \%(\mathrm{w} /$ v) fructose and $0.5 \%(\mathrm{v} / \mathrm{v}) \alpha$-thioglycerol) during $24 \mathrm{hr}$ (Ke \& Imai, 2014; Ke et al., 2013). The $\alpha$-thioglycerol is used to avoid the Maillard browning discoloration derived from the reactive ketone group of fructose, which can lead to autofluorescence (Dills, 1993). Grist et al. (2016) applied SeeDB to clear MCF-7 breast cancer spheroids with $370 \pm 90 \mu \mathrm{m}$ of the diameter that were transfected with fluorescent ubiquitination-based cell cycle indicator (FUCCI) for imaging by using 2PM. The clearing process was performed with the assistance of a microfluidic system, where spheroids were trapped. Then, clearing solutions $(20,40,60,80,100$, and $115 \%$ $(\mathrm{w} / \mathrm{v})$ fructose solutions with $0.5 \%(\mathrm{v} / \mathrm{v}) \alpha$-thioglycerol) were perfused through the microchannels using a syringe pump at a rate of approximately $20 \mu \mathrm{l} / \mathrm{min}$. The results demonstrated that the method induces a minimal reduction of the size of the spheroids, that is, the ratio of spheroids area before and after the clearing was 1.02 (Grist et al., 2016). This reduction is dependent on the flow rate used in the microfluidic channel, that is, higher flow rates lead to higher shrinkage, which may be related to the fluidic compressive forces or to the osmotic pressure. The transparency was slightly improved since the light transmittance increased to about $5.5 \%$ in the cleared spheroids (Grist et al., 2016). An analysis of the average FUCCI fluorescence intensity as a function of penetration depth into the sample demonstrated that the SeeDB method allowed to image the spheroids at depths greater than $250 \mu \mathrm{m}$, while the imaging of noncleared spheroid was limited to about $150 \mu \mathrm{m}$ (Grist et al., 2016). Nevertheless, the authors also observed that SeeDB solution increased the green fluorescence intensity of the spheroids (Grist et al., 2016), which was attributed to the formation of Maillard reaction products (Berke, Miola, David, Smith, \& Price, 2016).

Boutin \& Hoffman-Kim (2015) also applied the SeeDB method to clear rat adult neural stem cells (NSC) spheroids (mean diameter of $104.64 \pm 22.01 \mu \mathrm{m}$ ). Authors embedded the spheroids in 20,40 , and $60 \%(\mathrm{w} / \mathrm{v})$ fructose solutions (8 hr each). Then, spheroids were immersed in $80 \%(\mathrm{w} / \mathrm{v})$ and in $100 \%(\mathrm{w} / \mathrm{v})$ fructose solutions (12 hr each) and lastly during $24 \mathrm{hr}$ in $115 \%(\mathrm{w} / \mathrm{v})$ fructose, with all solutions containing $0.5 \%(\mathrm{v} / \mathrm{v}) \alpha$-thioglycerol. The spheroids after the clearing process presented moderate transparency in comparison to the noncleared spheroids (maintained in phosphate buffered saline [PBS]; Boutin \& Hoffman-Kim, 2015). Interestingly, despite being described that the SeeDB does not significantly influence the samples size (Grist et al., 2016; Ke et al., 2013), these authors observed that the spheroids shrink (104.64 \pm 22.01 vs $76.2 \pm 13.77 \mu \mathrm{m}$ in diameter) occurred as a consequence of the clearing process (Boutin \& Hoffman-Kim, 2015). Authors also observed that 4',6-diamidino-2phenylindole (DAPI)-labeled nuclei were difficult to distinguish. Furthermore, during the execution of the experimental protocol, the use of highly viscous solutions made the spheroids manipulation difficult, which resulted in the loss of many samples during the assay (Boutin \& Hoffman-Kim, 2015). Moreover, the viscosity of highly concentrated solutions of fructose also made challenging the acquisition of in-focus images containing both the spheroid and the background (Boutin \& Hoffman-Kim, 2015).

Alternatively, poor viscous clearing aqueous solutions with high RI can be obtained by using TDE, formamide (used in $\mathrm{Clear}^{T}$ and Clear $^{T 2}$ methods) or diatrizoic acid (used in FocusClear ${ }^{\text {TM }}$ method), as discussed hereafter.

\subsection{2 | TDE}

2,2'-Thiodiethanol (TDE) is a nontoxic, cheap, and water-soluble liquid displaying a low viscosity that has been widely used as a mounting media, since it has a RI (for 100\% TDE the RI is 1.52) similar to that of typical immersion oils used in fluorescence microscopy (Smyrek \& Stelzer, 2017; Staudt, Lang, Medda, Engelhardt, \& Hell, 2007). Moreover, TDE has also been used as a clearing agent, since it allows the control of the RI value by diluting it with water, that is, 30, 60, and $97 \%(\mathrm{v} / \mathrm{v})$ TDE:water solutions have $\mathrm{RI} \approx 1.39$, 1.45, and 1.52, respectively (Aoyagi, Kawakami, Osanai, Hibi, \& Nemoto, 2015; Costantini et al., 2015). Aoyagi et al. (2015) applied TDE solutions (30,60, and $97 \%(\mathrm{v} / \mathrm{v})$ in PBS) to clear mice brains and brain slices after their incubation for $6 \mathrm{hr}$ to 7 days, for improving the light penetration depth in both CLSM and 2PM. TDE has also been applied for the clearing of spheroids. Paiè et al. (2016) applied TDE to clear H2B-mCherry (histone H2B fluorescent nuclear reporter protein) expressing spheroids with an average diameter of $300 \mu \mathrm{m}$. For that purpose, authors dipped spheroids in different TDE solutions $(25,50$, and $68 \%(\mathrm{v} / \mathrm{v})$ in PBS) for $10 \mathrm{~min}$ each. Then, the high-throughput imaging of the spheroids was performed in an optofluidic lab-on-a-chip that integrates SPIM illumination and 
continuous sample delivery in a microfluidic channel. Briefly, after the clearing, the spheroids circulated at a constant speed $(20 \mu \mathrm{m} / \mathrm{s})$ in a microchannel containing a $0.1 \%(\mathrm{v} / \mathrm{v})$ TDE solution and their imaging was performed quickly ( $50 \mathrm{~ms}$ acquisition time) while passing through the light sheet. Combining the use of TDE with SPIM, it was possible to acquire images of the entire spheroid with a subcellular resolution that allowed the clear identification of the cells' nuclei, the cell counting and the observation of the cell mitosis (Paiè et al., 2016). Furthermore, it was possible to perform the 3D rendering of the acquired images and consequently obtain a $360^{\circ}$ detailed view of the spheroids (Paiè et al., 2016).

\subsection{3 | Clear $^{\top}$}

Formamide is a water-miscible polar solvent that was used for the first time by Kuwajima et al. (2013) in a method, termed Clear ${ }^{T}$, for clearing mice tissues (whole brains, brain sections, and embryos. In this method, samples are dipped in gradient solutions of formamide in water (20 up to $95 \%(\mathrm{v} / \mathrm{v})$ formamide) to homogenize the RI of the tissue to about 1.44 (Richardson \& Lichtman, 2015). The sample incubation time in each solution varies according to the sample size, for example, the clearing of whole brains took more than 2 days, while $20-1,000 \mu \mathrm{m}$ brain sections took less than $1 \mathrm{hr}$. Our research group also applied this method to allow the analysis of spheroids composed of normal human dermal fibroblasts (NHDF), with a diameter of $378 \pm 47 \mu \mathrm{m}$ (Costa, Moreira, de Melo-Diogo, \& Correia, 2018a). In this method, spheroids were incubated for $5 \mathrm{~min}$ in each formamide/water solution ( $20,40,80$, and $95 \%(v / v))$, followed by a final incubation step of $15 \mathrm{~min}$ in formamide $95 \%(\mathrm{v} / \mathrm{v})$, and then imaged by CLSM. The method improved the spheroids transparency and can be reversed by immersing the samples in PBS, which assures that the samples are not chemically modified by the clearing method Ke et al., 2013. The propidium iodide (PI) signal depth on the cleared spheroids was about $43 \%$ higher than that on the noncleared spheroids (207.72 \pm 19.54 vs. $145.71 \pm 15.66 \mu$ m; Costa et al., 2018a). Moreover, the modification of spheroid size was not significant, after the clearing process the spheroids presented a diameter of $407 \pm 27 \mu \mathrm{m}$, while the noncleared ones displayed a diameter of $378 \pm 47 \mu \mathrm{m}$ (Costa et al., 2018a). Nevertheless, although Clear $^{T}$ allowed a successful clearing of the samples, the formamidemediated protein denaturation can result in the quenching of the fluorescent proteins signal, as observed for green fluorescent protein (GFP) in mouse embryos (Kuwajima et al., 2013; Richardson \& Lichtman, 2015). Furthermore, Clear $^{T}$ may also reduce the $\mathrm{PI}$ fluorescence in spheroids (Costa et al., 2018a).

\subsubsection{Clear $^{\mathrm{T} 2}$}

The Clear ${ }^{T 2}$ method is an adaptation of the $\mathrm{Clear}^{T}$ with the objective of avoiding the formamide-mediated quenching of the fluorescent protein dyes. In this way, the Clear ${ }^{T 2}$ method described by Kuwajima et al. (2013) aimed to preserve the fluorescence of the samples by promoting the protein stabilization using polyethylene glycol (PEG)
8,000 Da in combination with formamide (Rawat, Raman Suri, \& Sahoo, 2010). In brief, the clearing of the biological samples (mice whole brains, brain sections, and embryos) was achieved through their immersion in graded series of formamide/PEG solutions (once in $25 / 10 \%$ (v/w) and then twice in 50/20\% (v/w); Kuwajima et al., 2013). Similarly, the time of incubation in each solution depends on the sample size (clearing of the whole mouse brains takes $\approx 18 \mathrm{hr}$, while 20-1,000 $\mu \mathrm{m}$ sections require less than $2 \mathrm{hr}$ ).

The Clear $^{T 2}$ method has been widely described for spheroids clearing (Boutin \& Hoffman-Kim, 2015; Boutin et al., 2018; Kabadi et al., 2015). Boutin and Hoffman-Kim (2015) used Clear ${ }^{\text {T2 }}$ to process C6 glioma, primary cortical neuron, and NSC spheroids by embedding them during $10 \mathrm{~min}$ in 25/10\% (v/w) formamide/PEG 8,000, followed by $5 \mathrm{~min}$ in $50 / 20 \%(\mathrm{v} / \mathrm{w}$ ) formamide/PEG 8,000 and lastly $60 \mathrm{~min}$ in $50 / 20 \%(v / w)$ formamide/PEG 8,000. The authors observed that no significant changes occurred in the volume of the NSC spheroids, after their clearing through $\mathrm{Clear}^{\mathrm{T} 2}$, that is, the diameter of cleared spheroids was $99.77 \pm 22.3 \mu \mathrm{m}$ and $104.64 \pm 22.01 \mu \mathrm{m}$ for the noncleared ones. Furthermore, the fluorescence signals of tracers (nucleus [DAPI]) and antibody immunostaining (Cadherin (Cy3), laminin (Dylight $\left.{ }^{\circledR} 488\right)$, nestin (Сy3), $\beta$-III tubulin (Cy3), S100 (Су3)) were detectable by CLSM at all depths within spheroids as well as the fine features within the center of the spheroids (Boutin \& Hoffman-Kim, 2015). The authors also described that prolonging the spheroid incubation time did not improve the clearing efficacy. Recently, the same research group also showed the applicability of the Clear $^{T 2}$ method for the imaging of immunostained spheroids composed of primary-derived postnatal rodent cortex cells by CLSM and MPM, to study in vitro the formation of endothelial cell capillarylike structures (Boutin et al., 2018).

In another study, Clear $^{T 2}$ was used in conjunction with immunostaining and biochemical staining for the imaging of spheroids of PLHC-1, LNCaP, and BEAS-2B cells by CLSM (Kabadi et al., 2015). Clear ${ }^{T 2}$ allowed the sharp visualization of the nuclear structure (Hoechst 33342) even in the center of the microtissue at depths superior to $75 \mu \mathrm{m}$ along the $z$-axis, contrasting with the maximum depth of $30 \mu \mathrm{m}$ in the noncleared spheroids (Kabadi et al., 2015). The method also allowed improved imaging of the spheroids' E-cadherin cell-cell interactions (Alexa Fluor ${ }^{\mathrm{TM}}$ 647), as well as the reactive oxygen species by using the CellROX® green assay (Kabadi et al., 2015).

In our research group, the Clear ${ }^{T 2}$ method was used for the clearing of PI-stained NHDF spheroids (diameter of $396.17 \pm 28.72 \mu \mathrm{m}$; Costa, Moreira, de Melo-Diogo, \& Correia, 2018b). In this study, the influence of PEG molecular weight $(4,000,8,000$, and $10,000 \mathrm{Da})$ on the clearing efficacy of the Clear ${ }^{T 2}$ method described by Boutin and Hoffman-Kim (2015) was evaluated. Independently of the PEG molecular weight, the Clear $^{T 2}$ clearing method contributed to increasing the spheroids transparency and for the preservation of the PI fluorescence intensity (Costa et al., 2018b). Furthermore, no significant changes in the size of the spheroids were observed for all the conditions tested. Nevertheless, the Clear $^{\text {T2 }}$ method performed using PEG 4,000 allowed a better PI signal depth, that is, the use of PEG 4,000 Da allowed the detection of the PI signal up to $211.67 \pm 16.81 \mu \mathrm{m}$, while for the PEG 8,000 and 
$10,000 \mathrm{Da}$ the fluorescence was only detected up to $183.89 \pm 14.13$ and $176.43 \pm 11.44 \mu \mathrm{m}$, respectively (Costa et al., 2018b). Moreover, spheroids fluorescence signal in the cross-section penetration depth was also improved by the use of PEG 4,000 Da (more than $24 \%$ compared to that of noncleared spheroids, at a penetration depth of $100 \mu \mathrm{m}$ in the z-axis; Costa et al., 2018b). These results may be related with the fact that smaller PEG chains can penetrate and distribute more easily through the spheroids and consequently promote the stabilization of the fluorescence probe in deeper regions of spheroids, thus allowing better imaging.

\subsection{5 | FocusClear ${ }^{\mathrm{TM}}$}

FocusClear $^{\mathrm{TM}}$ is a nontoxic, ready to use clearing solution that was originally developed for the processing of fruit fly brains and now is commercialized by CelExplorer Labs (U.S. Pat. No. 6472216B1 and China Taiwan Patent No. 206390). FocusClear ${ }^{\text {TM }}$ solution comprises a mixture of diatrizoic acid, the clearing agent, with dimethyl sulfoxide (DMSO), ethylenediaminetetraacetic acid, glucamine, $\beta$-nicotinamide adenine dinucleotide phosphate, sodium diatrizoate, and a derivative of polyoxyalkalene (Genina et al., 2010). In the literature, it was already demonstrated that FocusClear ${ }^{\mathrm{TM}}$ can enhance the transparency of several types of biological tissues (e.g. , mouse intestine (Fu et al., 2009) and mouse brain tissues (Moy et al., 2015)), as well as in spheroid samples (Chen et al., 2013). Chen et al. (2013) reported the clearing of crypt spheroids composed of intestinal stem cells isolated from mice, with approximately $300 \mu \mathrm{m}$ of thickness, by performing their immersion during $2 \mathrm{hr}$ in the FocusClear ${ }^{\mathrm{TM}}$ solution. Optical light microscopic observation revealed that it was possible to observe that spheroids maintained in PBS were opaque and dark in their central regions, while the cleared spheroids were almost transparent (Chen et al., 2013). In addition, the clearing process also allowed the visualization of the PI fluorescence signal across the spheroid by CLSM as well as the clear identification of the crypt spheroid shape and the protruded villi-crypt domains (Chen et al., 2013).

\section{2 | Delipidation and dehydration followed by RI matching}

To expedite the clearing process, researchers developed methods based on the lipids removal through the use organic solvents, that is, delipidation and dehydration, followed by RI matching methods (Spalteholz's technique, BABB, 3DISCO, and its derivatives). These approaches usually require two major steps: (a) initial dehydration of the sample, and (b) immersion of the samples in organic solvents (Figure 2). The initial dehydration step is usually performed using ethanol or methanol, since the solvents used in the following steps are not miscible with water (Seo et al., 2016). During the dehydration, step can also occur the removal of some lipids. After the water removal, the overall RI of the sample will increase since dehydrated proteins have a RI value $>1.5$, which is higher than that of water and lipids (1.33 and 1.44, respectively: Richardson \& Lichtman, 2015). Therefore, in the second step, samples are immersed in an organic solvent with higher RI (>1.5) to match the value of the dehydrated sample. Ideally, the organic solvents should also promote the removal of the remaining lipids since this will ensure a better homogeneous RI matching (Richardson \& Lichtman, 2015).

Although these methods result in improved transparencies in large samples in shorter periods of time, these approaches are well known for disrupting the fluorescence of some probes (e.g., GFP), due to the use of fixatives like ethanol, methanol, and acetone as well as organic solvents that cause structural changes in the proteins (Lee et al., 2016). Moreover, the samples dehydration can lead to their shrinkage, which can affect the fluorescence of some proteins. Fluorescent protein chromophores need water molecules to sustain their fluorescence emission (Richardson \& Lichtman, 2015). This sample shrinkage occurs due to the loss of the 3D hydrogen-bonding networks between the water $(70-80 \%$ of the samples) and the remaining intracellular constituents, an interaction that the dehydrating agents cannot fully replicate (Tainaka et al., 2016). Lastly, the organic solvents are toxic and can destroy the glues, as well as the equipment used in samples imaging.

\subsection{1 | Spalteholz's technique}

The first optical clearing method based on organic solvents was described a century ago by Spalteholz and it was developed to allow the histological analysis of large biological samples (e.g., entire organs and organ systems; Spalteholz, 1914). This method included an initial sample fixation with formalin, followed by its bleaching with hydrogen peroxide (used to perform hemoglobin discoloration which is responsible for the biological tissues visible light absorption). Then samples were dehydrated, using a series of alcohol concentrations, and immersed in a mixture of methyl salicylate and benzyl benzoate. Nevertheless, this method leads to samples shrinkage, browning, and also to the damage of the biological samples outer layers $(2-3 \mathrm{~cm})$, due to the formation of bubbles and cell death prompted by hydrogen peroxide (Alnuami, Zeedi, Qadri, \& Ashraf, 2008; Cumley, Crow, \& Griffen, 1939; Steinke \& Wolff, 2001). Additionally, the Spalteholz method can also affect the fluorescence emission by protein dyes (e.g., GFP loses its fluorescence upon exposure to oxyradicals that are produced by the hydrogen peroxide; Alnuami et al., 2008). Therefore, this method has not been used for the clearing of 3D cell cultures but is the basis of other clearing methods aimed for the spheroids processing (described hereafter).

\subsection{2 | Benzyl alcohol/benzyl benzoate}

Inspired by the Spalteholz method, Dent, Polson, and Klymkowsky (1989) and Dodt et al. (2007) reported the application of benzyl alcohol/benzyl benzoate (BABB)-based optical clearing protocol (also known as Murray's clear). The BABB method was initially used to clear mice embryos and whole brains for allowing their imaging by ultramicroscopy. The method includes an initial dehydration step based on the samples' incubation for 1 day in each ethanol solution (i.e., $30,50,70,80,96$, and twice in $100 \%(v / v)$ ethanol) with an 
additional $1 \mathrm{hr}$ in $100 \%(\mathrm{v} / \mathrm{v})$ hexane to achieve the maximum dehydration. Then, the samples are incubated with the clearing solution of benzylalcohol/benzyl benzoate $(1: 2(\mathrm{v} / \mathrm{v}))$ during 2 days.

Wenzel et al. (2014) adapted the BABB method to clear spheroids of T47D, DLD1, DU145, and primary colon cancer cells with a mean diameter of $\approx 400 \mu \mathrm{m}$. For that purpose, spheroids were initially dehydrated in ascending ethanol concentrations (50, 70, 85 , and $99 \%(\mathrm{v} / \mathrm{v}) ; 5$ min each) and then transferred to a BABB $(1: 1(\mathrm{v} / \mathrm{v}))$ solution. The authors demonstrated that the spheroids clearing allowed the visualization of the hypoxic (antipimonidazole antibody conjugated with FITC, a marker for hypoxia) and the dead cells (SYTOX ${ }^{\mathrm{TM}}$ Green stain for dead cells) in the inner regions of the spheroid, as well as the proliferative cells (Click-iT ${ }^{\mathrm{TM}}$ EdU Alexa Fluor $^{\mathrm{TM}} 555$ ) in their periphery using a custom build monolithic digital LSFM (mDSLM; Wenzel et al., 2014). Furthermore, the authors could evaluate the presence of dead cells in the spheroids core region after the administration of different compounds that target dormant cells (e.g., Antimycin, Cisplatin, Metformin, Paclitaxel, Rotenone, and Staurosporine). These results allowed the authors to confirm that the spheroids mimic the in vivo tumor microenvironment and additionally that this technique can be used in the high-throughput and high-content microscopy analysis for identifying substances that specifically target dormant cells in spheroids core regions (Wenzel et al., 2014).

Desmaison et al. (2018) also applied the BABB clearing and LSFM microscopy for the structural analysis of large HCT116 spheroids (average diameter of $650 \mu \mathrm{m}$. The clearing was performed through the sequential incubation of spheroids in 25, 50, 75, and 95\% (v/v) ethanol solutions and lastly in BABB solution (benzyl alcohol:benzyl benzoate, 1:2 $(\mathrm{v} / \mathrm{v}))$. After the clearing, the authors demonstrated that the imaging of the Pl-stained cell nuclei in the deep interior regions of the spheroids could be performed with improved resolution and detail. The obtained results revealed that the shape of the cell nuclei and the cell division is influenced by the spheroid growth conditions, that is, free growth over a nonadhesive surface versus physically confined growth conditions (spheroids embedded in agarose; Desmaison et al., 2018). Similarly, Schmitz et al. (2017) applied the BABB clearing method and mDSLM to image Draq5 stained T47D spheroids (displaying diameters ranging from $150 \mu \mathrm{m}$ to more than $500 \mu \mathrm{m}$. After the clearing procedure, the authors could perform the study of several parameters in spheroids, such as spheroids volume, number of cells, and cell nucleus volume by using the automated nuclei segmentation and image computational analysis.

Smyrek and Stelzer (2017) applied the BABB method to clear U343 spheroids (average diameter of $600 \mu \mathrm{m}$ ) with the aim to optimize an immunofluorescence staining protocol for 3D cell biology. The spheroids GM130 (cis-Golgi matrix protein), $\alpha$-tubulin, and $\beta$-catenin proteins were immunolabeled and the cell nucleus was stained with DAPI. For the clearing, spheroids were dehydrated with increasing concentrations of ethanol $(30,50,70,90,96$, and twice in $100 \%(\mathrm{v} / \mathrm{v}), 2 \mathrm{~min}$ each) and then transferred to the BABB solution (benzyl alcohol:benzyl benzoate, 1:2 (v/v)) until the transparency was attained (Smyrek \& Stelzer, 2017). After, the authors quantitatively analyzed the specificity and homogeneity of the stain, as well as the Alexa Fluor $^{\mathrm{TM}}$ 568, Alexa Fluor ${ }^{\mathrm{TM}}$ 488, and DAPI signal intensity. Overall, the results demonstrated that the best protocol for the spheroids immunofluorescence labeling included: (a) fixation of the spheroids during $15 \mathrm{~min}$ with $4 \%$ paraformaldehyde at room temperature (RT); (b) detergent-based permeabilization by Triton X-100, during $15 \mathrm{~min}$, at RT; (c) blockage of unspecific binding sites with a solution of $0.1 \%$ bovine serum albumin, $0.2 \%$ Triton $\mathrm{X}-100$, $0.05 \%$ Tween- $20 \%$ and $10 \%$ goat serum for $1 \mathrm{hr}$ at RT; (d) incubation of the first antibody at $37^{\circ} \mathrm{C}$ during $18-24 \mathrm{hr}$; (e) incubation of the second antibody at $37^{\circ} \mathrm{C}$ during $4 \mathrm{hr}$; (f) dehydration and clearing by BABB during $15 \mathrm{~min}$; and (g) imaging by mDSLM (Smyrek \& Stelzer, 2017).

Although the utilization of the BABB clearing method can result in samples with high tissue transparency, the use of ethanol/ methanol during the dehydration step still results in a reduction of the size of the spheroids, which can impact the analysis of the data extracted from these samples (Smyrek \& Stelzer, 2017).

\subsubsection{D imaging of solvent-cleared organs}

Since the ethanol dehydration step used in the BABB method results in the quenching of the proteins fluorescence (Becker, Jährling, Saghafi, Weiler, \& Dodt, 2012; Feuchtinger et al., 2016), Becker et al. (2012) investigated alternative chemicals (RI between 1.5 and 1.7) that could be used for samples dehydration. The results obtained demonstrated that the utilization of tetrahydrofuran (THF) in brain hemispheres has a similar dehydration effect to that of ethanol, with the advantage of the background fluorescence intensity be considerably reduced and the intensity of the fluorescence signal be enhanced (Becker et al., 2012). This solvent adaptation was termed the 3DISCO clearing method. In this procedure, the samples were initially dehydrated by using grading THF solutions ( $50,70,80 \%$ (v) v)) followed by their incubation in THF $100 \%(v / v), 1-3$ times, dichloromethane, and then in dibenzylether (Erturk et al., 2012). The incubation time of the samples depends on its size, that is, few hours for small organs (few millimeters in size) such as spinal cords, mammary glands or lymph nodes and a day for large organs such as the brain.

3DISCO protocol variations have been also developed, such as iDISCO (immunolabeling-enabled 3D imaging of solvent-cleared organs), UDISCO (ultimate 3D imaging of solvent-cleared organs), and FDISCO (DISCO with superior fluorescence preserving capability), that were describe by Renier et al. (2014), Pan et al. (2016), and Qi et al. (2019), respectively. In the iDISCO, samples are pretreated with methanol, Triton X-100, and dimethyl sulfoxide (DMSO) to facilitate the antibody penetration and consequently improve the whole-organ immunolabeling (Renier et al., 2014). On the other hand, the uDISCO was developed to significantly reduce the size of the samples (up to $65 \%$ of its original size) by using tertbutanol as a dehydration reagent, which can make possible the observation of large samples, with sizes up to the whole mouse body 
(Pan et al., 2016). The FDISCO method allows overcoming the quenching of the fluorescent proteins that happens in the 3DISCO method by controlling the $\mathrm{pH}$ and temperature conditions during the clearing procedure (Qi et al., 2019).

Despite the 3DISCO and its modified methods being widely used for the clearing of several animal samples, its application in spheroids processing is yet to be described.

\section{3 | Delipidation and hyperhydration followed by RI matching}

The delipidation and hyperhydration followed by RI matching methods (Scale and CUBIC) use solutions of urea (denaturing agent) and Triton X-100 (nonionic detergents) for promoting the clearing of the samples (Figure 2). During this process, the detergents will remove the lipids that have high $\mathrm{RI}(\approx 1.44)$ and therefore reduce the sample overall RI. Furthermore, the urea will penetrate the cells denaturing the folded proteins $(R I \approx 1.43)$, which also reduces the sample RI (Richardson \& Lichtman, 2015). Moreover, the urea also creates an osmotic gradient that will favor the water diffusion into the sample (hydration) and therefore homogenizes the overall RI value to $\approx 1.38$ (Richardson \& Lichtman, 2015).

These methods are easy to perform and have a high clearing capacity, due to the removal of lipids from the sample, without leading to fluorescence quenching and toxicity problems associated with the solvent-based clearing methods (Seo et al., 2016). Furthermore, this approach is also compatible with immunoblotting techniques (e.g., immunofluorescent labeling with antibodies) since the cellular membrane is permeable to the antibodies after its treatment with the detergent (Mattei, Lira, Perez, \& Riske, 2017). On the other hand, the samples can undergo hydration-induced expansion, which is undesirable during the analysis of the spheroids (Seo et al., 2016).

\subsection{1 | Scale}

Hama et al. (2015) developed the Scale clearing method for the imaging of brain samples obtained from mice and patients. These researchers initially observed that the use of $8 \mathrm{M}$ urea solutions can improve the tissue transparency, but also results in great tissue expansion. In this way, these authors tested different Scale solutions composed of urea, as well as Triton X-100 and glycerol with the objective to reduce the expansion of the samples and improve the tissue transparency. The Triton X-100 detergent was used to promote the lipids removal from the sample and therefore improve the sample transparency. Glycerol was added to counterbalance the urea-induced tissue expansion, assist the dehydration, and to target the lipophilic tissue regions. Among the different solutions investigated, the better clearing results were obtained when ScaleA2 ( $4 \mathrm{M}$ urea, $10 \%(w / v)$ glycerol and $0.1 \%(w / v)$ Triton X-100; RI $\approx 1.378)$ solution were used. However, the clearing took several weeks (e.g., more than 2 weeks for mouse embryos) and the samples became highly fragile, difficult to handle, and tissue swelling was still observed. Having this in mind, in a subsequent work this study group developed the ScaleS clearing method, where solutions composed of urea $(4 \mathrm{M})$, Triton $\mathrm{X}-100(\leq 0.2 \%(\mathrm{v} / \mathrm{v}))$ and sorbitol $(20,27,36.4$, and $40 \%(w / v))$ were used (Hama et al., 2015). The sorbitol replaced the glycerol due to its clearing properties and superior potential to reduce the sample volume expansion caused by urea.

Scale clearing solutions have also been employed for processing spheroid samples (Boutin \& Hoffman-Kim, 2015; Hama et al., 2015). ScaleA2 solution (4 M urea, $0.2 \%(w / v)$ Triton X-100\% and $10 \%(w / w)$ glycerol in water) was used to clear NSC spheroids (with an average diameter of $104.64 \pm 22.01 \mu \mathrm{m}$ ) for imaging by CLSM (Boutin \& Hoffman-Kim, 2015). In this work, a two times higher concentration of Triton X-100, in comparison to that described by Hama et al. (2015), was used for improving the samples clearing. The spheroids clearing was achieved by performing 3 cycles of $24 \mathrm{hr}$ incubation with fresh ScaleA2 solutions. Further, the authors observed that the realization of the ScaleA2 protocol during longer periods did not improve the samples clearing. Moreover, the spheroids processing with the ScaleA2 resulted in a size expansion to an average diameter of $139.2 \pm 32.64 \mu \mathrm{m}$ (Boutin \& Hoffman-Kim, 2015). Lastly, the authors reported that the spheroids, in comparison to those incubated with PBS, become mechanically fragile after the clearing process.

In another study, the ScaleSQ (one of the Scale solutions investigated by Hama et al. (2015), composed of $9.1 \mathrm{M}$ urea and $22.5 \%(\mathrm{w} / \mathrm{v})$ sorbitol; $\mathrm{RI} \approx 1.439)$ was used to clear MCF-7 breast cancer spheroids (diameter $=370 \pm 90 \mu \mathrm{m}$; Grist et al., 2016). The method increased the average transmitted light intensity through the spheroids, that is, the transmittance after the clearing increased by 7.5\%. Furthermore, the authors observed that the ScaleSQ significantly increased the $\mathrm{FUCCl}$ fluorescence intensity in the deeper regions of the spheroid and also the depth until each spheroid could be imaged (more than $250 \mu \mathrm{m}$ deeper in the z-axis) by 2PM (Grist et al., 2016). Nevertheless, the clearing solution induced the sample swelling, about 1.7-times higher spheroids area after the clearing and appear to mediate a shift in the color, that is, the FUCCl orange fluorescence (characteristic of the cells' nucleus in interphase stages of their cell cycle) appear more yellow (Grist et al., 2016).

\subsection{2 | Clear, unobstructed brain/body imaging cocktails, and computational analysis}

Another clearing method that uses urea and Triton X-100 (like the Scale solutions) is the clear, unobstructed brain/body imaging cocktails and computational analysis (CUBIC). This method was initially developed for the clearing of mouse whole-brain imaging with LSFM (Susaki et al., 2014), and it involves the samples treatment with two clearing solutions, termed ScaleCUBIC-1 (also known as Reagent 1; 25\% (w/w) urea, 25\% (w/w) N,N,N',N'-tetrakis(2-hydroxypropyl) ethylenediamin and $15 \%(\mathrm{w} / \mathrm{w})$ Triton X-100) and ScaleCUBIC-2 (also known as Reagent 2; 50\% (w/v) sucrose, 25\% $(\mathrm{w} / \mathrm{v})$ urea, $10 \%(\mathrm{w} / \mathrm{v})$ 2,2',2'-nitrilotriethanol and $0.1 \%(\mathrm{v} / \mathrm{v})$ Triton 
$\mathrm{X}-100 ; \mathrm{RI} \approx 1.48$ ). The amino alcohol N,N,N,N-tetrakis(2-hydroxypropyl) ethylenediamine in the Reagent 1 solution was used as a tissue solubilizing agent which decolorizes blood and makes the organs much more transparent (Tainaka et al., 2014). In brief, the CUBIC protocol was performed by immersing the whole-brain samples in the Reagent 1 for 6-7 days (renewing the media after the first 3 days of incubation), then washing them several times with PBS followed by their incubation with $20 \%(\mathrm{w} / \mathrm{v})$ sucrose in PBS and then a final immersion in the Reagent 2 solution for 2-7 days.

Masson et al. (2015) applied the CUBIC clearing method to clear HCT116 spheroids (average diameter of $400 \mu \mathrm{m}$ ) to develop a highresolution in-depth imaging approach of optically cleared thick spheroids using an adaptive SPIM. For this purpose, spheroids were immersed with the Reagent 1 solution for either 2 or 4 days (temperature $37^{\circ} \mathrm{C}$ ), then samples were transferred into a fresh Reagent 1 solution for additional 3-4 days. Then, spheroids were washed several times with PBS and incubated with $20 \%(\mathrm{w} / \mathrm{v})$ sucrose and $50 \%(\mathrm{w} / \mathrm{v})$ glycerol solution for a minimum of $2 \mathrm{hr}$. Lastly, spheroids were immersed in the Reagent 2 solution with gentle shaking for 1-2 days, before the imaging. The optical clearing guaranteed high transparency and reduced the aberration patterns of the spheroids, contributing to the high-resolution in-depth imaging of the Alexa Fluor ${ }^{\mathrm{TM}} 594$ (Click-iT ${ }^{\mathrm{TM}} \mathrm{EdU}$ ) and H2B-mCherry signals (Masson et al., 2015). Moreover, the authors demonstrated that, after the clearing procedure, the spheroids' images improved in quality, namely the fluorescence intensity and contrast.

\section{4 | Hydrogel embedding followed by delipidation and RI matching}

The hydrogel embedding followed by delipidation and RI matching optical clearing methods comprehends the CLARITY and its derived approaches (e.g., PACT and PARS). These methods involve three major steps. The first step comprises the perfusion of the sample with a mixture of paraformaldehyde (or formaldehyde), acrylamide, and bisacrylamide monomers (that form a polyacrylamide gel in the sample after its polymerization). Then, the lipids are removed from the sample-gel hybrid by using a solution of an ionic detergent, namely sodium dodecyl sulfate (SDS). Lastly, the hydrogel-embedded samples are immersed on a RI-matching solution (e.g., FocusClear ${ }^{\mathrm{TM}}$ ) to render it transparency.

The gel will provide support for the biological structures to sustain their initial integrity, but it will also stabilize the proteins, nucleic acids, and other small molecules by cross-linking them with the mesh of the gel (Silvestri et al., 2016). Despite the sample being immersed in a hydrogel, its porous nature makes possible the penetration and diffusion of exogenous macromolecules, such as immunolabeling dyes and fluorochromes (Feuchtinger et al., 2016). Since CLARITY-based methods include the lipids removal, it is possible to achieve a great clearing in a similar way to other delipidation-based methods. However, due to the sample protection in a gel, the proteins concentration and folding is not affected in the same extent like when the methods containing harsh solvents or high concentrations of detergents. Additionally, since the removal of the lipid is performed by using SDS instead of organic solvents (like those used in the BABB and 3DISCO methods), the fluorescence is preserved (e.g., GFP fluorescence; Chung et al., 2013).

\subsection{1 | CLARITY and derived methods}

The original clear lipid-exchanged acrylamide-hybridized rigid imaging/immunostaining/in situ hybridization-compatible tissue-hydrogel (CLARITY) method (also known as active CLARITY) was proposed in 2013 by Chung et al. (2013) to clear adult mouse whole brains and human brain samples of $500 \mu \mathrm{m}$ in thickness. Authors, initially infused a mixture of $4 \%(w / v)$ paraformaldehyde, $4 \%(w / v)$ acrylamide, $0.05 \%(\mathrm{w} / \mathrm{v})$ bisacrylamide and $0.25 \%(\mathrm{w} / \mathrm{v}) 2,2^{\prime}$-azobis [2-(2-imidazolin-2-yl)propane] dihydrochloride (VA-044; thermal radical initiator) into the tissues. Then, after the hydrogel polymerization $\left(3 \mathrm{hr}\right.$ at $\left.37^{\circ} \mathrm{C}\right)$, samples were subjected to an electric field potential (created by a custom electrophoresis system) and a 4\% (w/ v) SDS solution ( 1 or 2 days) to actively remove the lipidic content. Lastly, the samples were incubated in FocusClear ${ }^{\mathrm{TM}}$ ( 2 days for mouse brains and 1 day for human brain samples).

Nevertheless, the active CLARITY method requires specific equipment, as well as an expensive commercial RI-matching clearing solution (FocusClear ${ }^{\mathrm{TM}}$ ). Additionally, the strong electric field can change the molecular and structural integrity of the sample (Seo et al., 2016). Therefore, several CLARITY-derived methods emerged, such as PACT (passive clarity technique), PARS (Perfusion-assisted agent release in situ), and others (reviewed in detail by Jensen and Berg (2017) and Du, Hou, Zhang, and Li (2018)). The PACT and PARS methods use lower concentrations of fixatives and hydrogel monomers in conjugation with higher SDS concentrations $(8 \%(w / v))$, to facilitate and increase the passive diffusion of SDS into the sample and thus obtain a greater clearing without using the electrophoresis system. Additionally, both methods usually use RIMS (Refractive Index Matching Solution composed mainly of Histodenz or Sorbitol), which is a more economical RI-matching solution than FocusClear ${ }^{\mathrm{TM}}$ (Yang et al., 2014b). In the PACT method, sample-hydrogel hybrid is simply merged with an SDS solution, while in the PARS method the removal of the lipids is performed by perfusing continually the sample with the SDS solution (Yang et al., 2014b).

CLARITY-based methods were also used to clear spheroids. Silva Santisteban, Rabajania, Kalinina, Robinson, and Meier (2018) used CLARITY and a microfluidic system to clear an image human-derived adipose stem cells spheroids ( $200 \pm 50 \mu \mathrm{m}$ in diameter) by CLSM. In brief, after spheroids trapping in the chambers of the microfluidic chip, these were perfused with a solution of paraformaldehyde, acrylamide, and bisacrylamide $(4: 4: 0.25 \%(\mathrm{v} / \mathrm{v}))$ for $1 \mathrm{hr}$ (replaced every $10 \mathrm{~min}$ ). After $2 \mathrm{hr}$ of gel polymerization (VA-044 at $37^{\circ} \mathrm{C}$ ), the lipids were removed by using $0.14 \mathrm{M} \mathrm{SDS}$ solution $(\mathrm{pH}=8.5)$ that was renewed every $30 \mathrm{~min}$ during a total of 3 days. All solutions (except the thermal radical initiator) were flushed with a flow rate of $2 \mu \mathrm{l} / \mathrm{min}$ using a flush time per chamber of $20 \mathrm{~s}$. At last, X-Clarity ${ }^{\mathrm{TM}}$ (Logos Biosystems) was introduced as mounting media to match the RI. The 
results demonstrated that the clearing time of the spheroids off-chip took 10-14 days, while this process was reduced to 2 days when a microfluidic system was used. Furthermore, the authors also investigated the influence of the $\mathrm{pH}$ value in the media surrounding the hydrogel-embedded spheroids on the swelling and shrinkage of the gel (Silva Santisteban et al., 2018). These changes lead to the creation of osmotic pressure and thus facilitate the lipids extraction from the spheroids. For that purpose, the hydrogel-embedded spheroids were subjected to incubation cycles $(10 \mathrm{~min})$ in SDS solution ( $\mathrm{pH}$ 8.5) and phosphate buffer ( $\mathrm{pH}$ 6.5). In these conditions, the clearing time was reduced to $5 \mathrm{hr}$. Lastly, authors confirmed that the osmotic pump cycles did not perturb the nuclear structure and the proteins position, which was studied by labeling the cell nucleus (DAPI), the mitochondria (anti-COX IV antibody labeled with Alexa Fluor $^{\mathrm{TM}}$ 647), and cytoplasm (anti-GAPDH labeled with Atto488 ${ }^{\mathrm{TM}}$; Silva Santisteban et al., 2018). Nevertheless, the authors observed that the spheroids shrank to $150 \mu \mathrm{m}$ in diameter after the clearing process (Silva Santisteban et al., 2018).

Chen and co-workers also investigated the application of microfluidic technology to clear whole intact spheroids (e.g., MCF-7 spheroids with $250 \mu \mathrm{m}$ of diameter and GFP-expressing U87MG spheroids with a diameter of $450 \mu \mathrm{m}$ ) using a CLARITY-based method and perform imaging by CLSM (Chen et al., 2016). Upon spheroids loading in the microfluidic system, a solution of $2-8 \%(w / v)$ acrylamide, $4 \%(\mathrm{w} / \mathrm{v})$ formaldehyde, and $2.5 \%(\mathrm{w} / \mathrm{v})$ of VA-044 was infused at $600-800 \mu \mathrm{l} / \mathrm{h}$ through the spheroids for $20 \mathrm{~min}$. After $2 \mathrm{hr}$ of gel polymerization $\left(37^{\circ} \mathrm{C}\right), 8 \%(\mathrm{w} / \mathrm{v})$ SDS was infused at $800 \mu \mathrm{l} / \mathrm{h}$ during 5-10 min. Lastly, RIMS (88\% (w/v) lohexol, 2.5\% (w/v) 1,4diazabicyclo[2.2.2]octane, $50 \mathrm{mM}$ sodium borate, and $0.01 \%(\mathrm{w} / \mathrm{v})$ sodium azide) was infused into the spheroids $(800 \mu \mathrm{l} / \mathrm{h}$ for tumor spheroids) during 10-15 min. Authors observed that without the acrylamide treatment, the spheroid structure is deformed due to the fluidic forces applied during the clearing process (Chen et al., 2016). Moreover, increasing the acrylamide concentration decreases the extent of tissue shrinkage (e.g., $80-90 \%$ of the spheroids initial volume was maintained when used $8 \%(\mathrm{w} / \mathrm{v})$ acrylamide). On the other hand, SDS solution flow led to the lipophilic dye (DiO) fluorescence loss but simultaneously did not affect the spheroids stain with Transferrin-647 as well as facilitated the spheroids staining with DAPI and Phalloidin-488 (Chen et al., 2016). The results obtained also demonstrated that the imaging depth was increased by $150 \%$ for MCF-7 spheroids (labeled with CellTracker ${ }^{\text {TM }}$ Red), and 250\% for U87MG-GFP spheroids, when compared to the noncleared spheroids. Furthermore, authors also verified that the CLARITY-based method performed in the microfluidic system could be used for live/dead imaging of the spheroids treated with drugs (doxorubicin, imatinib, or sunitinib) and using LIVE/DEAD ${ }^{\circledR}$ Fixable Near-IR Dead Cell Stain.

\section{4 | OUTLOOK AND FUTURE DIRECTIONS}

Nowadays, the combination of optical clearing methods with advanced fluorescence microscopes improved significantly the visualization of large biological samples (penetration depth, image contrast, and spatial resolution) obtained from animals or humans, and more recently for 3D large spheroids. Nevertheless, it is expected that future research will further result in increased clearing efficacies and improved imaging of thick samples. Currently, the combination of the strengths of different methods has been supporting the development of procedures that allow to obtain better clearing and imaging without affecting the structure and the endogenous/exogenous fluorescence of the sample, as discussed by Yu et al. (2018). For example, FRUIT optical clearing method was developed by merging the principles of SeeDB and Scale protocols, that is, mixing urea with fructose to decrease the overall viscosity of the SeeDB fructose solution and improve tissue penetration and clearing (Hou et al., 2015).

Moreover, since the clearing capacity of the methods is influenced by the location and concentration of the clearing agent in the sample, it would be interesting to investigate physical or chemical procedures to enhance the clearing agents penetration

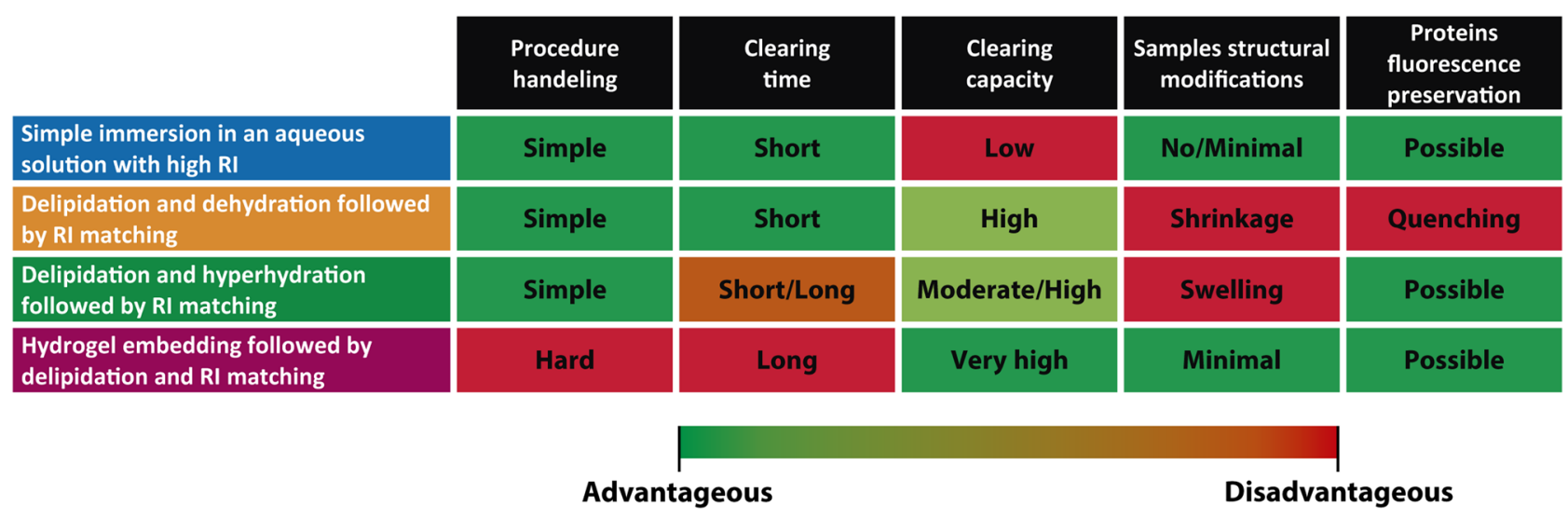

FIGURE 3 Overview of the optical clearing methods categories (simple immersion in an aqueous solution with high RI; delipidation and dehydration followed by RI matching; delipidation and hyperhydration followed by RI matching; and hydrogel embedding followed by delipidation and RI matching) application in spheroids. RI: refractive index [Color figure can be viewed at wileyonlinelibrary.com] 
(Ariel, 2017; Zhu et al., 2013). In fact, optical clearing methods (e.g., SWITCH and PRESTO) were recently designed to actively improve the penetration of macromolecules into deep regions of tissues by altering electrical, physical and chemical factors (Lee et al., 2016).

On the other hand, researchers are still searching for optical clearing methods that permit the imaging of the cells without damaging or killing them, which will impact on the realization of timecourse experiments (Calve, Ready, Huppenbauer, Main, \& Neu, 2015; Neu, Novak, Gilliland, Marshall, \& Calve, 2015). In fact, all the clearing methods described so far damage the cells (e.g., cells fixation and organic solvents utilization; Calve et al., 2015). Therefore, it is crucial to identify a RI-matching agent that does not harm the spheroids (Boothe, Hilbert, Heide, Berninger, \& Huttner, 2017) Recently, lodixanol has been investigated as a nontoxic medium supplement and RI-matching agent that improves image quality in live-imaging experiments involving primary cell cultures, planarians, zebrafish and human cerebral organoids (Boothe et al., 2017).

The development of a unharmful optical clearing method will also open several windows in terms of the therapeutic applications. In other words, the increased light penetration in cleared tissues may be useful for photo-based therapies, as well as drug-delivery monitoring.

\section{5 | CONCLUSION}

For more than 100 years, optical clearing methods have been used for the clearing of large biological samples obtained from animals. These methods have been developed to fulfill the following two major premises: (a) provide high transparency without affecting the initial structure and size of the sample; and (b) preserve endogenous and exogeneous fluorescence (e.g., immunofluorescence), which is fundamental for the analysis of the proteins of interest.

More recently, optical clearing methods started to be explored for allowing the whole imaging of large 3D spheroids, as reviewed in this article. Till nowadays, SeeDB, TDE, Clear ${ }^{T}, \mathrm{Clear}^{\mathrm{T} 2}$, FocusClear ${ }^{\mathrm{TM}}$, BABB, Scale, CUBIC, and CLARITY optical clearing methods have been used for spheroids imaging under different types of microscopes (2PM, adaptive SPIM, CLSM, LSFM, and mDSLM). Gathering the information available in the literature it is possible to organize the four major types of optical clearing methods accordingly to their simplicity of execution, duration, clearing capacity, as well as their influence on samples integrity and preservation of the fluorescence of the proteins (Figure 3). Nevertheless, there are several other optical clearing methods (e.g., 3DISCO, FRUIT, PRESTO, and SWITCH) that are yet to be investigated in spheroids.

With future efforts, it will be possible to obtain a highthroughput-compatible approach to combine clearing, high-content imaging, and analysis of spheroids. Thus, optical clearing methods will contribute significantly to the widespread use of spheroids in the evaluation of different cellular events in normal and diseased human tissues.

\section{ACKNOWLEDGMENTS}

This work was supported by FEDER funds through the POCl COMPETE 2020 - Operational Programme Competitiveness and Internationalisation in Axis I - Strengthening research, technological development, and innovation (Project POCl-01-0145-FEDER007491) and National Funds by FCT - Foundation for Science and Technology (Project UID/Multi /00709/2013). The funding from CENTRO-01-0145-FEDER-028989 and POCI-01-0145-FEDER031462 is also acknowledged. André F. Moreira and Elisabete C. Costa acknowledge for their grants: SFRH/BD/109482/2015 and SFRH/BD/103507/2014, respectively. The funders had no role in the decision to publish or in the preparation of the manuscript.

\section{CONFLICT OF INTEREST}

The authors declare that there is no conflict of interest.

\section{ORCID}

Ilídio J. Correia (D) http://orcid.org/0000-0003-1613-9675

\section{REFERENCES}

Achilli, T.-M., Meyer, J., \& Morgan, J. R. (2012). Advances in the formation, use and understanding of multi-cellular spheroids. Expert Opinion on Biological Therapy, 12(10), 1347-1360. https:// doi.org/10.1517/14712598.2012.707181

Alnuami, A. A., Zeedi, B., Qadri, S. M., \& Ashraf, S. S. (2008). Oxyradicalinduced GFP damage and loss of fluorescence. International Journal of Biological Macromolecules, 43(2), 182-186. https://doi.org/10.1016/j. ijbiomac.2008.05.002

Aoyagi, Y., Kawakami, R., Osanai, H., Hibi, T., \& Nemoto, T. (2015). A rapid optical clearing protocol using 2,2'-thiodiethanol for microscopic observation of fixed mouse brain. PLoS One, 10(1), e0116280. https:// doi.org/10.1371/journal.pone.0116280

Ariel, P. (2017). A beginner's guide to tissue clearing. The International Journal of Biochemistry \& Cell Biology, 84, 35-39. https://doi.org/10. 1016/j.biocel.2016.12.009

Azaripour, A., Lagerweij, T., Scharfbillig, C., Jadczak, A. E., Willershausen, B., \& Van Noorden, C. J. F. (2016). A survey of clearing techniques for 3D imaging of tissues with special reference to connective tissue. Progress in Histochemistry and Cytochemistry, 51(2), 9-23. https://doi. org/10.1016/j.proghi.2016.04.001

Bassnett, S. (2009). On the mechanism of organelle degradation in the vertebrate lens. Experimental Eye Research, 88(2), 133-139. https:// doi.org/10.1016/j.exer.2008.08.017

Becker, K., Jährling, N., Saghafi, S., Weiler, R., \& Dodt, H.-U. (2012). Chemical clearing and dehydration of GFP expressing mouse brains. PLoS One, 7(3), e33916. https://doi.org/10.1371/journal. pone.0033916

Benninger, R. K. P., \& Piston, D. W. (2013). Two-photon excitation microscopy for the study of living cells and tissues. Current Protocols in Cell Biology, 4, 4.11.1-4.11.24. https://doi.org/10.1002/0471143030. cb0411s59

Berke, I. M., Miola, J. P., David, M. A., Smith, M. K., \& Price, C. (2016). Seeing through musculoskeletal tissues: Improving in situ imaging of bone and the lacunar canalicular system through optical clearing. PLoS One, 11(3), e0150268. https://doi.org/10.1371/ journal.pone.0150268 
Bigio, I. J., \& Bown, S. G. (2004). Spectrroscopic sensing of cancer and cancer therapy: Current status of translational research. Cancer Biology \& Therapy, 3(3), 259-267.

Boothe, T., Hilbert, L., Heide, M., Berninger, L., \& Huttner, W. B. (2017). A tunable refractive index matching medium for live imaging cells, tissues and model organisms. elife, 6, e27240. https://doi.org/10. 7554/eLife. 27240

Boutin, M. E., \& Hoffman-Kim, D. (2015). Application and assessment of optical clearing methods for imaging of tissue-engineered neural stem cell spheres. Tissue Engineering, Part C: Methods, 21(3), 292-302. https://doi.org/10.1089/ten.TEC.2014.0296

Boutin, M. E., Kramer, L. L., Livi, L. L., Brown, T., Moore, C., \& HoffmanKim, D. (2018). A three-dimensional neural spheroid model for capillary-like network formation. Journal of Neuroscience Methods, 299, 55-63. https://doi.org/10.1016/j.jneumeth.2017.01.014

Calve, S., Ready, A., Huppenbauer, C., Main, R., \& Neu, C. P. (2015). Optical clearing in dense connective tissues to visualize cellular connectivity in situ. PLoS One, 10(1), e0116662. https://doi.org/10.1371/journal. pone.0116662

Chen, Y., Tsai, Y.-H., Liu, Y.-A., Lee, S.-H., Tseng, S.-H., \& Tang, S.-C. (2013). Application of three-dimensional imaging to the intestinal crypt organoids and biopsied intestinal tissues. The Scientific World Journal, 2013, 624342-624349. https://doi.org/10.1155/2013/624342

Chen, Y. Y., Silva, P. N., Syed, A. M., Sindhwani, S., Rocheleau, J. V., \& Chan, W. C. (2016). Clarifying intact 3D tissues on a microfluidic chip for high-throughput structural analysis. Proceedings of the National Academy of Sciences, 113(52), 14915-14920. https://doi.org/10. 1073/pnas.1609569114

Choi, W., Fang-Yen, C., Badizadegan, K., Oh, S., Lue, N., Dasari, R. R., \& Feld, M. S. (2007). Tomographic phase microscopy. Nature Methods, 4(9), 717-719. https://doi.org/10.1038/nmeth1078

Chung, K., Wallace, J., Kim, S.-Y., Kalyanasundaram, S., Andalman, A. S., Davidson, T. J., ... Deisseroth, K. (2013). Structural and molecular interrogation of intact biological systems. Nature, 497, 332-337. https://doi.org/10.1038/nature12107

Cirello, V., Vaira, V., Grassi, E. S., Vezzoli, V., Ricca, D., Colombo, C., ... Fugazzola, L. (2017). Multicellular spheroids from normal and neoplastic thyroid tissues as a suitable model to test the effects of multikinase inhibitors. Oncotarget, 8(6), 9752-9766. https://doi.org/ 10.18632/oncotarget.14187

Combs, C. A., \& Shroff, H. (2017). Fluorescence microscopy: A Concise guide to current imaging methods. Current Protocols in Cell Biology, 79, https://doi.org/10.1002/0471142301.ns0201s50. 2.1.1-2.1.25

Costa, E. C., Moreira, A. F., de Melo-Diogo, D., \& Correia, I. J. (2018a). ClearT immersion optical clearing method for intact 3D spheroids imaging through confocal laser scanning microscopy. Optics \& Laser Technology, 106, 94-99. https://doi.org/10.1016/j.optlastec.2018.04. 002

Costa, E. C., Moreira, A. F., de Melo-Diogo, D., \& Correia, I. J. (2018b). Polyethylene glycol molecular weight influences the Clear T2 optical clearing method for spheroids imaging by confocal laser scanning microscopy. Journal of Biomedical Optics, 23(5), 055003. https://doi. org/10.1117/1.JBO.23.5.055003

Costa, E. C., Moreira, A. F., de Melo-Diogo, D., Gaspar, V. M., Carvalho, M. P., \& Correia, I. J. (2016). 3D tumor spheroids: An overview on the tools and techniques used for their analysis. Biotechnology Advances, 34(8), 1427-1441. https://doi.org/10.1016/j.biotechadv.2016.11.002

Costantini, I., Ghobril, J.-P., Di Giovanna, A. P., Mascaro, A. L. A., Silvestri, L., Müllenbroich, M. C., ... Pavone, F. S. (2015). A versatile clearing agent for multi-modal brain imaging. Scientific Reports, 5, 9808. https:// doi.org/10.1038/srep09808

Cumley, R. W., Crow, J. F., \& Griffen, A. B. (1939). Clearing specimens for the demonstration of bone. Stain Technology, 14(1), 7-11. https://doi. org/10.3109/10520293909110285
Dent, J. A., Polson, A. G., \& Klymkowsky, M. W. (1989). A whole-mount immunocytochemical analysis of the expression of the intermediate filament protein vimentin in Xenopus. Development, 105(1), 61-74.

Desmaison, A., Guillaume, L., Triclin, S., Weiss, P., Ducommun, B., \& Lobjois, V. (2018). Impact of physical confinement on nuclei geometry and cell division dynamics in 3D spheroids. Scientific Reports, 8(1), 8785. https://doi.org/10.1038/s41598-018-27060-6

Dills, W. L., Jr. (1993). Protein fructosylation: Fructose and the Maillard reaction. American Journal of Clinical Nutrition, 58(5 Suppl), 779s-787s. https://doi.org/10.1093/ajcn/58.5.779S

Dodt, H. U., Leischner, U., Schierloh, A., Jahrling, N., Mauch, C. P., Deininger, K., \& Becker, K. (2007). Ultramicroscopy: Three-dimensional visualization of neuronal networks in the whole mouse brain. Nature Methods, 4(4), 331-336. https://doi.org/10.1038/nmeth1036

Du, H., Hou, P., Zhang, W., \& Li, Q. (2018). Advances in CLARITY-based tissue clearing and imaging. Experimental and Therapeutic Medicine, 16(3), 1567-1576. https://doi.org/10.3892/etm.2018.6374

Duval, K., Grover, H., Han, L. H., Mou, Y., Pegoraro, A. F., Fredberg, J., \& Chen, Z. (2017). Modeling physiological events in 2D vs. 3D Cell Culture. Physiology (Bethesda), 32(4), 266-277. https://doi.org/10. 1152/physiol.00036.2016

Edmondson, R., Broglie, J. J., Adcock, A. F., \& Yang, L. (2014). Threedimensional cell culture systems and their applications in drug discovery and cell-based biosensors. Assay and Drug Development Technologies, 12(4), 207-218. https://doi.org/10.1089/adt.2014.573

Eiraku, M., Takata, N., Ishibashi, H., Kawada, M., Sakakura, E., Okuda, S., ... Sasai, Y. (2011). Self-organizing optic-cup morphogenesis in threedimensional culture. Nature, 472, 51-56. https://doi.org/10.1038/ nature09941

Eiraku, M., Watanabe, K., Matsuo-Takasaki, M., Kawada, M., Yonemura, S., Matsumura, M., ... Sasai, Y. (2008). Self-organized formation of polarized cortical tissues from ESCs and its active manipulation by extrinsic signals. Cell Stem Cell, 3(5), 519-532. https://doi.org/10. 1016/j.stem.2008.09.002

Erturk, A., Becker, K., Jahrling, N., Mauch, C. P., Hojer, C. D., Egen, J. G., ... Dodt, H. U. (2012). Three-dimensional imaging of solvent-cleared organs using 3DISCO. Nature Protocols, 7(11), 1983-1995. https://doi. org/10.1038/nprot.2012.119

Feuchtinger, A., Walch, A., \& Dobosz, M. (2016). Deep tissue imaging: A review from a preclinical cancer research perspective. Histochemistry and Cell Biology, 146(6), 781-806. https://doi.org/10.1007/s00418016-1495-7

Fu, Y.-Y., Lin, C.-W., Enikolopov, G., Sibley, E., Chiang, A.-S., \& Tang, S. -C. (2009). A microtome-free 3-dimensional confocal imaging method for visualization of mouse intestine with subcellular-level resolution. Gastroenterology, 137(2), 453-465. https://doi.org/10.1053/j.gastro. 2009.05.008

Genina, E. A., Bashkatov, A. N., \& Tuchin, V. V. (2010). Tissue optical immersion clearing. Expert Review of Medical Devices, 7(6), 825-842. https://doi.org/10.1586/erd.10.50

Graf, B. W., \& Boppart, S. A. (2010). Imaging and analysis of threedimensional cell culture models. Methods in Molecular Biology, 591, 211-227. https://doi.org/10.1007/978-1-60761-404-3_13

Grist, S. M., Nasseri, S. S., Poon, T., Roskelley, C., \& Cheung, K. C. (2016). On-chip clearing of arrays of 3-D cell cultures and micro-tissues. Biomicrofluidics, 10(4), 044107. https://doi.org/10.1063/1.4959031

Gualda, E. J., Simão, D., Pinto, C., Alves, P. M., \& Brito, C. (2014). Imaging of human differentiated 3D neural aggregates using light sheet fluorescence microscopy. Frontiers in Cellular Neuroscience, 8, 221. https://doi.org/10.3389/fncel.2014.00221.

Ham, S. L., Joshi, R., Luker, G. D., \& Tavana, H. (2016). Engineered breast cancer cell spheroids reproduce biologic properties of solid tumors. Advanced Healthcare Materials, 5(21), 2788-2798. https://doi.org/10. 1002/adhm.201600644 
Ham, S. L., Thakuri, P. S., Plaster, M., Li, J., Luker, K. E., Luker, G. D., \& Tavana, H. (2018). Three-dimensional tumor model mimics stromal breast cancer cells signaling. Oncotarget, 9(1), 249-267. https://doi. org/10.18632/oncotarget.22922

Hama, H., Hioki, H., Namiki, K., Hoshida, T., Kurokawa, H., Ishidate, F., ... Miyawaki, A. (2015). ScaleS: An optical clearing palette for biological imaging. Nature Neuroscience, 18(10), 1518-1529. https://doi.org/10. 1038/nn.4107

Hama, H., Kurokawa, H., Kawano, H., Ando, R., Shimogori, T., Noda, H., ... Miyawaki, A. (2011). Scale: A chemical approach for fluorescence imaging and reconstruction of transparent mouse brain. Nature Neuroscience, 14(11), 1481-1488. https://doi.org/10.1038/nn.2928

Hamilton, G. (1998). Multicellular spheroids as an in vitro tumor model. Cancer Letters, 131(1), 29-34. https://doi.org/10.1016/S03043835(98)00198-0

Haseda, K., Kanematsu, K., Noguchi, K., Saito, H., Umeda, N., \& Ohta, Y. (2015). Significant correlation between refractive index and activity of mitochondria: Single mitochondrion study. Biomedical Optics Express, 6(3), 859-869. https://doi.org/10.1364/BOE.6.000859

Hou, B., Zhang, D., Zhao, S., Wei, M., Yang, Z., Wang, S., ... Jiang, T. (2015). Scalable and Dil-compatible optical clearance of the mammalian brain. Frontiers in Neuroanatomy, 9, 19. https://doi.org/10.3389/fnana.2015. 00019

Hudu, S. A., Alshrari, A. S., Syahida, A., \& Sekawi, Z. (2016). Cell culture, technology: Enhancing the culture of diagnosing human diseases. Journal of Clinical and Diagnostic Research, 10(3), DE01-DE05. https:// doi.org/10.7860/JCDR/2016/15837.7460

Jensen, K. H. R., \& Berg, R. W. (2017). Advances and perspectives in tissue clearing using CLARITY. Journal of Chemical Neuroanatomy, 86, 19-34. https://doi.org/10.1016/j.jchemneu.2017.07.005

Jukes, J. M., Both, S. K., Leusink, A., Sterk, L. M., van Blitterswijk, C. A., \& de Boer, J. (2008). Endochondral bone tissue engineering using embryonic stem cells. Proceedings of the National Academy of Sciences, 105(19), 6840-6845. https://doi.org/10.1073/pnas.0711662105

Kabadi, P. K., Vantangoli, M. M., Rodd, A. L., Leary, E., Madnick, S. J., Morgan, J. R., ... Boekelheide, K. (2015). Into the depths: Techniques for in vitro three-dimensional microtissue visualization. Biotechniques, 59(5), 279-286. https://doi.org/10.2144/000114353

Kapałczyńska, M., Kolenda, T., Przybyła, W., Zajączkowska, M., Teresiak, A., Filas, V., ... Lamperska, K. (2018). 2D and 3D cell cultures - a comparison of different types of cancer cell cultures. Archives of Medical Science, 14(4), 910-919. https://doi.org/10.5114/aoms.2016. 63743

Ke, M.-T., Fujimoto, S., \& Imai, T. (2013). SeeDB: A simple and morphology-preserving optical clearing agent for neuronal circuit reconstruction. Nature Neuroscience, 16(8), 1154-1161. https://doi. org/10.1038/nn.3447

Ke, M. T., \& Imai, T. (2014). Optical clearing of fixed brain samples using SeeDB. Current Protocols in Neuroscience, 66, 2.22.1-2.22.19. https:// doi.org/10.1002/0471142301.ns0222s66

Keereweer, S., Van Driel, P. B., Snoeks, T. J., Kerrebijn, J. D., Baatenburg de Jong, R. J., Vahrmeijer, A. L., ... Löwik, C. W. (2013). Optical imageguided cancer surgery: Challenges and limitations. Clinical Cancer Research, 19(14), 3745-3754. https://doi.org/10.1158/1078-0432. CCR-12-3598

Kehat, I., Kenyagin-Karsenti, D., Snir, M., Segev, H., Amit, M., Gepstein, A., \& Gepstein, L. (2001). Human embryonic stem cells can differentiate into myocytes with structural and functional properties of cardiomyocytes. Journal of Clinical Investigation, 108(3), 407-414. https://doi. org/10.1172/JCI12131

Khawar, I. A., Park, J. K., Jung, E. S., Lee, M. A., Chang, S., \& Kuh, H. J. (2018). Three dimensional mixed-cell spheroids mimic stromamediated chemoresistance and invasive migration in hepatocellular carcinoma. Neoplasia, 20(8), 800-812. https://doi.org/10.1016/j.neo. 2018.05.008
Kuwajima, T., Sitko, A. A., Bhansali, P., Jurgens, C., Guido, W., \& Mason, C. (2013). ClearT: A detergent- and solvent-free clearing method for neuronal and non-neuronal tissue. Development, 140(6), 1364-1368. https://doi.org/10.1242/dev.091844

Langenbach, F., Berr, K., Naujoks, C., Hassel, A., Hentschel, M., Depprich, R., ... Handschel, J. (2011). Generation and differentiation of microtissues from multipotent precursor cells for use in tissue engineering. Nature Protocols, 6(11), 1726-1735. https://doi.org/10. 1038/nprot.2011.394

Lazzari, G., Nicolas, V., Matsusaki, M., Akashi, M., Couvreur, P., \& Mura, S. (2018). Multicellular spheroid based on a triple coculture: A novel 3D model to mimic pancreatic tumor complexity. Acta Biomaterialia, 78, 296-307. https://doi.org/10.1016/j.actbio. 2018.08.008

Lee, E., Kim, H. J., \& Sun, W. (2016). See-through technology for biological tissue: 3-Dimensional visualization of macromolecules. International Neurourology Journal, 20(Suppl 1), S15-S22. https://doi.org/10.5213/ inj.1632630.315

Lumelsky, N., Blondel, O., Laeng, P., Velasco, I., Ravin, R., \& McKay, R. (2001). Differentiation of embryonic stem cells to insulin-secreting structures similar to pancreatic islets. Science, 292(5520), 1389-1394. https://doi.org/10.1126/science.1058866

Marques, P. E., Oliveira, A. G., Chang, L., Paula-Neto, H. A., \& Menezes, G. B. (2015). Understanding liver immunology using intravital microscopy. Journal of Hepatology, 63(3), 733-742. https://doi.org/10.1016/ j.jhep.2015.05.027

Masson, A., Escande, P., Frongia, C., Clouvel, G., Ducommun, B., \& Lorenzo, C. (2015). High-resolution in-depth imaging of optically cleared thick samples using an adaptive SPIM. Scientific Reports, 5, 16898. https:// doi.org/10.1038/srep16898

Mattei, B., Lira, R. B., Perez, K. R., \& Riske, K. A. (2017). Membrane permeabilization induced by Triton X-100: The role of membrane phase state and edge tension. Chemistry and Physics of Lipids, 202, 28-37. https://doi.org/10.1016/j.chemphyslip.2016.11.009

Moy, A. J., Capulong, B. V., Saager, R. B., Wiersma, M. P., Lo, P. C., Durkin, A. J., \& Choi, B. (2015). Optical properties of mouse brain tissue after optical clearing with FocusClear. Journal of Biomedical Optics, 20(9), 95010. https://doi.org/10.1117/1.jbo.20.9.095010

Neu, C. P., Novak, T., Gilliland, K. F., Marshall, P., \& Calve, S. (2015). Optical clearing in collagen- and proteoglycan-rich osteochondral tissues. Osteoarthritis and Cartilage, 23(3), 405-413. https://doi.org/10. 1016/j.joca.2014.11.021

Paiè, P., Bragheri, F., Bassi, A., \& Osellame, R. (2016). Selective plane illumination microscopy on a chip. Lab on a Chip, 16(9), 1556-1560. https://doi.org/10.1039/C6LC00084C

Pampaloni, F., Ansari, N., \& Stelzer, E. H. (2013). High-resolution deep imaging of live cellular spheroids with light-sheet-based fluorescence microscopy. Cell and Tissue Research, 352(1), 161-177. https://doi.org/ 10.1007/s00441-013-1589-7.

Pan, C., Cai, R., Quacquarelli, F. P., Ghasemigharagoz, A., Lourbopoulos, A., Matryba, P., \& Plesnila, N. (2016). Shrinkage-mediated imaging of entire organs and organisms using uDISCO. Nature Methods, 13(10), 859-867. https://doi.org/10.1038/nmeth.3964

Qi, Y., Yu, T., Xu, J., Wan, P., Ma, Y., Zhu, J., ... Zhu, D. (2019). FDISCO: Advanced solvent-based clearing method for imaging whole organs. Science Advances, 5(1), eaau8355. https://doi.org/10.1126/sciadv. aau 8355

Rawat, S., Raman Suri, C., \& Sahoo, D. K. (2010). Molecular mechanism of polyethylene glycol mediated stabilization of protein. Biochemical and Biophysical Research Communications, 392(4), 561-566. https://doi. org/10.1016/j.bbrc.2010.01.067

Renier, N., Wu, Z., Simon, D. J., Yang, J., Ariel, P., \& Tessier-Lavigne, M. (2014). iDISCO: A simple, rapid method to immunolabel large tissue samples for volume imaging. Cell, 159(4), 896-910. https://doi.org/10. 1016/j.cell.2014.10.010 
Reynaud, E. G., Kržič, U., Greger, K., \& Stelzer, E. H. (2008). Light sheetbased fluorescence microscopy: More dimensions, more photons, and less photodamage. HFSP Journal, 2(5), 266-275. https://doi.org/10. 2976/1.2974980

Richardson, D. S., \& Lichtman, J. W. (2015). Clarifying tissue clearing. Cell, 162(2), 246-257. https://doi.org/10.1016/j.cell.2015.06.067

Sandberg, R., \& Ernberg, I. (2005). The molecular portrait of in vitro growth by meta-analysis of gene-expression profiles. Genome Biology, 6(8), R65. https://doi.org/10.1186/gb-2005-6-8-r65

Santi, P. A. (2011). Light sheet fluorescence microscopy: A review. Journal of Histochemistry \& Cytochemistry, 59(2), 129-138. https://doi.org/10. 1369/0022155410394857

Schmitz, A., Fischer, S. C., Mattheyer, C., Pampaloni, F., \& Stelzer, E. H. K. (2017). Multiscale image analysis reveals structural heterogeneity of the cell microenvironment in homotypic spheroids. Scientific Reports, 7, 43693. https://doi.org/10.1038/srep43693

Seo, J., Choe, M., \& Kim, S. Y. (2016). Clearing and labeling techniques for large-scale biological tissues. Molecules and Cells, 39(6), 439-446. https://doi.org/10.14348/molcells.2016.0088

Silva Santisteban, T., Rabajania, O., Kalinina, I., Robinson, S., \& Meier, M. (2018). Rapid spheroid clearing on a microfluidic chip. Lab on a Chip, 18(1), 153-161. https://doi.org/10.1039/C7LC01114H

Silvestri, L., Costantini, I., Sacconi, L., \& Pavone, F. S. (2016). Clearing of fixed tissue: A review from a microscopist's perspective. Journal of Biomedical Optics, 21(8), 081205. https://doi.org/10.1117/1.jbo.21.8.081205

Smyrek, I., \& Stelzer, E. H. K. (2017). Quantitative three-dimensional evaluation of immunofluorescence staining for large whole mount spheroids with light sheet microscopy. Biomedical Optics Express, 8(2), 484-499. https://doi.org/10.1364/BOE.8.000484

Souza, A., Ferreira, I., Marangoni, K., Bastos, V., \& Goulart, V. (2016). Advances in cell culture: More than a century after cultivating cells. Journal of Biotechnology and Biomaterials, 6, 1-4. https://doi.org/10. 4172/2155-952X.1000221

Spalteholz, W. (1914). Über das Durchsichtigmachen von menschlichen und tierischen Präparaten und seine theoretischen Bedingungen, nebst Anhang: Über Knochenfärbung. Leipzig.

Staudt, T., Lang, M. C., Medda, R., Engelhardt, J., \& Hell, S. W. (2007). 2,2'thiodiethanol: A new water soluble mounting medium for high resolution optical microscopy. Microscopy Research and Technique, 70(1), 1-9. https://doi.org/10.1002/jemt.20396

Steinke, H., \& Wolff, W. (2001). A modified Spalteholz technique with preservation of the histology. Annals of Anatomy, 183(1), 91-95. https://doi.org/10.1016/s0940-9602(01)80020-0

Suga, H., Kadoshima, T., Minaguchi, M., Ohgushi, M., Soen, M., Nakano, T., ... Sasai, Y. (2011). Self-formation of functional adenohypophysis in three-dimensional culture. Nature, 480(7375), 57-62. https://doi.org/ 10.1038/nature10637

Susaki, E. A., Tainaka, K., Perrin, D., Kishino, F., Tawara, T., Watanabe, T. M., ... Ueda, H. R. (2014). Whole-brain imaging with single-cell resolution using chemical cocktails and computational analysis. Cell, 157(3), 726-739. https://doi.org/10.1016/j.cell.2014.03.042

Susaki, E. A., \& Ueda, H. R. (2016). Whole-body and whole-organ clearing and imaging techniques with single-cell resolution: Toward organism-level systems biology in mammals. Cell Chemical Biology, 23(1), 137-157. https://doi.org/10.1016/j.chembiol.2015. 11.009
Tainaka, K., Kubota, S. I., Suyama, T. Q., Susaki, E. A., Perrin, D., UkaiTadenuma, M., ... Ueda, H. R. (2014). Whole-body imaging with singlecell resolution by tissue decolorization. Cell, 159(4), 911-924. https:// doi.org/10.1016/j.cell.2014.10.034

Tainaka, K., Kuno, A., Kubota, S. I., Murakami, T., \& Ueda, H. R. (2016). Chemical principles in tissue clearing and staining protocols for whole-body cell profiling. Annual Review of Cell and Developmental Biology, 32, 713-741. https://doi.org/10.1146/annurev-cellbio111315-125001

Tuchin, V. V. (2015). Tissue optics and photonics: Light-tissue interaction. Journal of Biomedical Photonics \& Engineering, 1(2), 98-134. https://doi. org/10.18287/jbpe-2015-1-2-98

Weber, P., Schickinger, S., Wagner, M., \& Angres, B., et al. (2015). Monitoring of Apoptosis in 3D Cell Cultures by FRET and Light Sheet Fluorescence Microscopy. International Journal of Molecular Sciences, 16(3), 5375-5385. https://doi.org/10.3390/ijms16035375.

Wenzel, C., Riefke, B., Gründemann, S., Krebs, A., Christian, S., Prinz, F., ... Steigemann, P. (2014). 3D high-content screening for the identification of compounds that target cells in dormant tumor spheroid regions. Experimental Cell Research, 323(1), 131-143. https://doi.org/ 10.1016/j.yexcr.2014.01.017

Wilson, J. D., Cottrell, W. J., \& Foster, T. H. (2007). Index-of-refractiondependent subcellular light scattering observed with organellespecific dyes. Journal of Biomedical Optics, 12(1), 014010. https://doi. org/10.1117/1.2437765

Yang, B., Treweek, J. B., Kulkarni, R. P., Deverman, B. E., Chen, C. K., Lubeck, E., ... Gradinaru, V. (2014b). Single-cell phenotyping within transparent intact tissue through whole-body clearing. Cell, 158(4), 945-958. https://doi.org/10.1016/j.cell.2014.07.017

Yoon, No, D., Lee, K. H., Lee, J., \& Lee, S. H. (2015). 3D liver models on a microplatform: Well-defined culture, engineering of liver tissue and liver-on-a-chip. Lab on a Chip, 15(19), 3822-3837. https://doi.org/10. 1039/c5lc00611b

Yu, T., Qi, Y., Gong, H., Luo, Q., \& Zhu, D. (2018). Optical clearing for multiscale biological tissues. Journal of Biophotonics, 11(2), 1-13. https://doi.org/10.1002/jbio.201700187

Zhang, Q., Zhong, L., Tang, P., Yuan, Y., Liu, S., Tian, J., \& Lu, X. (2017). Quantitative refractive index distribution of single cell by combining phase-shifting interferometry and AFM imaging. Scientific Reports, 7(1), 2532. https://doi.org/10.1038/s41598-017-02797-8

Zhu, D., Larin, K. V., Luo, Q., \& Tuchin, V. V. (2013). Recent progress in tissue optical clearing. Laser \& Photonics Reviews, 7(5), 732-757. https://doi.org/10.1002/Ipor.201200056

Zipfel, W. R., Williams, R. M., \& Webb, W. W. (2003). Nonlinear magic: Multiphoton microscopy in the biosciences. Nature Biotechnology, 21, 1369-1377. https://doi.org/10.1038/nbt899

How to cite this article: Costa EC, Silva DN, Moreira AF, Correia IJ. Optical clearing methods: An overview of the techniques used for the imaging of 3D spheroids.

Biotechnology and Bioengineering. 2019;1-22.

https://doi.org/10.1002/bit.27105 